William R. Wiley

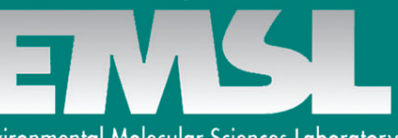

Environmental Molecular Sciences Laboratory

\title{
Computational Chemistry for Nuclear Waste Characterization and Processing: Relativistic Quantum Chemistry of Actinides
}

$\begin{array}{ll}\text { R.J. Harrison } & \text { M. Minkoff } \\ \text { D. Bernholdt } & \text { J.A. Nichols } \\ \text { B.E. Bursten } & \text { J. Nieplocha } \\ \text { W.A. de Jong } & \text { R. Pitzer } \\ \text { D.A. Dixon } & \text { L.R. Pratt } \\ \text { K.G. Dyall } & \text { G. Schreckenbach } \\ \text { W.C. Ermler } & \text { M. Seth } \\ \text { G.I. Fann } & \text { R.L. Shepard } \\ \text { P.J. Hay } & \text { R. Stevens } \\ \text { N. Ismail-Büchner } & \text { J.L. Tilson } \\ \text { R.A. Kendall } & \text { A.F. Wagner } \\ \text { J. Li } & \text { Q. Wang } \\ \text { M.M. Marino } & \text { T.L. Windus } \\ \text { C. Marsden } & \text { A.T. Wong } \\ \text { R.L. Martin } & \text { Z. Zhang }\end{array}$

Theory, Modeling and Simulation

August 2002

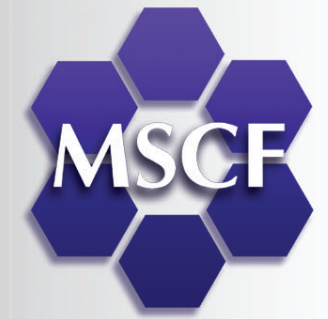


This research was performed in part using the Molecular Science Computing Facility (MSCF) in the William R. Wiley Environmental Molecular Sciences Laboratory, a national scientific user facility sponsored by the U.S. Department of Energy's Office of Biological and Environmental Research and located at the Pacific Northwest National Laboratory. Pacific Northwest is operated for the Department of Energy by Battelle.

\title{
DISCLAIMER
}

This report was prepared as an account of work sponsored by an agency of the United States Government. Neither the United States Government nor any agency thereof, nor Battelle Memorial Institute, nor any of their employees, makes any warranty, express or implied, or assumes any legal liability or responsibility for the accuracy, completeness, or usefulness of any information, apparatus, product, or process disclosed, or represents that its use would not infringe privately owned rights. Reference herein to any specific commercial product, process, or service by trade name, trademark, manufacturer, or otherwise does not necessarily constitute or imply its endorsement, recommendation, or favoring by the United States Government or any agency thereof, or Battelle Memorial Institute. The views and opinions of authors expressed herein do not necessarily state or reflect those of the United States Government or any agency thereof.

\author{
PACIFIC NORTHWEST NATIONAL LABORATORY \\ operated by \\ BATTELLE \\ for the \\ UNITED STATES DEPARTMENT OF ENERGY \\ under Contract DE-ACO6-76RLO183O
}

http://www.pnl.gov/main/publications/external/technical_reports/pnnl-14001.pdf

PNNL-14001, Published by Pacific Northwest National Laboratory for the

Environmental Molecular Sciences Laboratory 


\section{Computational Chemistry for Nuclear Waste Characterization and Processing: Relativistic Quantum Chemistry of Actinides}

$\begin{array}{ll}\text { R.J. Harrison } & \text { M. Minkoff } \\ \text { D. Bernholdt } & \text { J.A. Nichols } \\ \text { B.E. Bursten } & \text { J. Nieplocha } \\ \text { W.A. de Jong } & \text { R. Pitzer } \\ \text { D.A. Dixon } & \text { L.R. Pratt } \\ \text { K.G. Dyall } & \text { G. Schreckenbach } \\ \text { W.C. Ermler } & \text { M. Seth } \\ \text { G.I. Fann } & \text { R.L. Shepard } \\ \text { P.J. Hay } & \text { R. Stevens } \\ \text { N. Ismail-Büchner } & \text { J.L. Tilson } \\ \text { R.A.Kendall } & \text { A.F. Wagner } \\ \text { J. Li } & \text { Q. Wang } \\ \text { M.M. Marino } & \text { T.L. Windus } \\ \text { C. Marsden } & \text { A.T. Wong } \\ \text { R.L. Martin } & \text { Z. Zhang }\end{array}$

August 2002

Published by Pacific Northwest National Laboratory for the Environmental Molecular Sciences Laboratory 


\section{Computational Chemistry for Nuclear Waste Characterization and Processing: Relativistic Quantum Chemistry of Actinides}

\section{$\underline{\text { Research Team Members }}$}

Members: Robert. J. Harrison, Jeffrey A. Nichols, Rick A. Kendall, David A. Dixon, Theresa L. Windus, W. A. (Bert) de Jong, Zhiyong Zhang, Jarek Nieplocha, George I. Fann

Institution: Pacific Northwest National Laboratory

Funding: 1. "Computational Chemistry for Nuclear Waste Characterization and Processing: Relativistic Quantum Chemistry of Actinides," HPCC (MICS/OCTR/OS). 2. "Architectural Design Criteria for f-Block Metal Sequestering Agents," EMSP. 3. "Chemical Speciation of Strontium, Americium, and Curium in High Level Waste: Predictive Modeling of Phase Partitioning During Tank Processing," EMSP

Members: Ron L. Shepard, Jeffrey L. Tilson, Albert F. Wagner, Rick Stevens, Michael Minkoff, Michael Seth

Institution: Argonne National Laboratory

Funding: "Computational Chemistry for Nuclear Waste Characterization and Processing: Relativistic Quantum Chemistry of Actinides," HPCC (MICS/OCTR/OS).

Members: P. Jeffrey Hay, Richard L. Martin, Lawrence R. Pratt, George Schreckenbach Institution: Los Alamos National Laboratory

Funding: "LDRD Competency Development Thrust in Actinide Molecular Science [Theory Component]."

Members: Adrian T. Wong

Institution: NERSC/LBNL

Members: Walter C. Ermler, Maria M. Marino

Institution: Stevens Institute of Technology

Members: Kenneth G. Dyall

Institution: Eloret

Funding: "Computational Chemistry for Nuclear Waste Characterization and Processing:

Relativistic Quantum Chemistry of Actinides," HPCC (MICS/OCTR/OS).

Members: Russell Pitzer,Qi Wang, Bruce E. Bursten, Jun Li

Institution: The Ohio State University

Funding: "The Electronic Structure of Heavy Element Complexes," DOE BES, Heavy Element Chemistry Program (Bursten and Li). 
Members: David Bernholdt

Institution: Syracuse University

Funding: "Computational Chemistry for Nuclear Waste Characterization and Processing:

Relativistic Quantum Chemistry of Actinides," HPCC (MICS/OCTR/OS).

Members: Colin Marsden, Nina Ismail-Büchner

Institution: University of Toulouse (France)

$\underline{\text { Number of Hours Allocated for the Past Three Years }}$

Year 1: 1,000,000 hours

Year 2: 700,000 hours

Year 3: 700,000 hours

\section{Number of Hours Used in the Past Year}

Year 1: 981,290 hours

Year 2: 700,000 hours

Year 3: 700,000 hours 


\section{Overview of Accomplishments and Activities}

In the course of the 3 years we have conducted calculations on molecular structures containing actinides, lanthanides, and other heavy elements. Our calculations were done at the relativistically-correct, all-electron, 4-component calculations (DHF, MP2, and CCSD(T)), using density functional theory (DFT) with relativistic effective core potentials (RECPs), and various other methodologies. We studied the ground- and excited state structures, energetics, vibrational frequencies, and NMR, excitation and ionization spectra. In addition a considerable amount of codes and methodologies have been developed during the GC3 period, enabling us to do the extensive research described in this final report, and providing researchers worldwide with new computational chemistry tools. In this section we will give a brief overview of our activities and accomplishments, grouped by each research institution. A more extensive overview can be found in the appendices containing the full yearly reports.

\section{$\underline{\text { Pacific Northwest National Laboratory }}$}

The research that was performed at PNNL consists of two parts, applications and code/methodology development. We will address both aspects of the research.

\section{Application Work}

\section{$\underline{\text { Benchmark Calculations }}$}

We have performed fully relativistically, all-electron, 4-component Dirac-Hartree-Fock MP2 and $\operatorname{CCSD}(\mathrm{T})$ calculations on the free uranyl ion. These results are serving as a benchmark for approximate relativistic methods, which are used to study the larger complexes. In addition fully relativistic calculations were done on the excited state of the uranyl ion in a crystal structure, using a point charge model for simulating the environment. Fully relativistic calculations on the ${ }^{2} \Pi_{1 / 2}{ }^{2} \Pi_{3 / 2}$ ground state spin-orbit splitting curve of $\mathrm{SiF}$ have been performed. The calculated results, agree to around $1 \mathrm{~cm}^{-1}$ with the experimental data, an error of less then $1 \%$. Fully relativistic calculations have been performed on the potential energy curves of the chlorine molecule. The ground state and all excited states, dissociating to neutral atoms, and their spectroscopic properties have been calculated. The results are currently used to interpret experimental data.

\section{$\underline{\text { RECP Calculations on Molecular Properties of Actinide Complexes }}$}

From the outset of this work a premium was placed upon strong interaction with experimental researchers at PNNL and elsewhere, and relevance to DOE mission areas. Carbonates of uranyl are of interest because carbonate is a ubiquitous ligand in ground-water systems and forms strong aqueous complexes that impact solubility and mobility of ions in environmental systems and greatly complicates speciation. Halides and nitrates are important due to

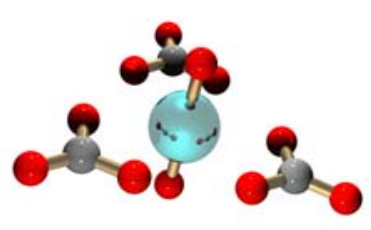
their presence in tank waste, and uranium oxy-fluorides are especially important since they form when $\mathrm{UF}_{6}$ leaks into the atmosphere. Acetates serve as a 
model for isosaccharinic acid, which is a decay product of cellulose. For these reasons we have examined the binding, structure and vibrational frequencies of a very wide array of carbonates (uranyl tri-carbonate is shown in figure 1), halides, oxy-fluorides, nitrates, acetates, and hydrates of primarily uranyl, and also some other actinyls and actinide ions. Excellent agreement has been obtained with available experimental data in the literature and the work is making direct contact with two experimental groups at PNNL. We have also studied the structure and vibrational frequencies of the ground and excited electronic states of various uranyl species including the tetrachloride and hydrates in order to support laser experiments for speciation of uranyl at mineral surfaces. We have studied the ground and excited states of several aqua uranylanion $\left(\mathrm{UO}_{2} \mathrm{~A}^{+}\left(\mathrm{H}_{2} \mathrm{O}\right)_{n}, \mathrm{~A}=\mathrm{Cl}^{-}, \mathrm{F}^{-}\right.$and $\left.\mathrm{OH}^{-}\right)$complexes. AS an example we show the $\mathrm{UO}_{2} \mathrm{~F}\left(\mathrm{H}_{2} \mathrm{O}\right)_{3}{ }^{+}$complex in figure 2. Structures and vibrational frequencies are computed with DFT using NWChem and compared with available experimental results. The excited state structures for simple aqua uranyl-anion complexes, $\mathrm{UO}_{2} \mathrm{OH}\left(\mathrm{H}_{2} \mathrm{O}\right)_{4}{ }^{+}, \mathrm{UO}_{2} \mathrm{~F}\left(\mathrm{H}_{2} \mathrm{O}\right)_{4}{ }^{+}$and $\mathrm{UO}_{2} \mathrm{Cl}\left(\mathrm{H}_{2} \mathrm{O}\right)_{4}{ }^{+}$were optimized. The calculated excitation energies are in the order of $\mathrm{UO}_{2} \mathrm{OH}\left(\mathrm{H}_{2} \mathrm{O}\right)_{4}{ }^{+}>\mathrm{UO}_{2} \mathrm{~F}\left(\mathrm{H}_{2} \mathrm{O}\right)_{4}{ }^{+}>\mathrm{UO}_{2} \mathrm{Cl}\left(\mathrm{H}_{2} \mathrm{O}\right)^{+}$from B3LYP calculations and $\mathrm{UO}_{2} \mathrm{~F}\left(\mathrm{H}_{2} \mathrm{O}\right)_{4}{ }^{+}>$

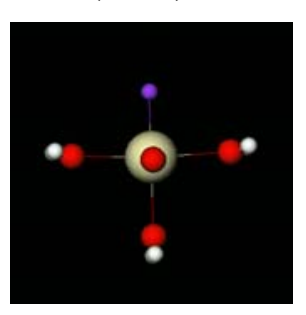

Figure 2. $\mathrm{UO}_{2} \mathrm{~F}\left(\mathrm{H}_{2} \mathrm{O}\right)_{3}{ }^{+}$ $\mathrm{UO}_{2} \mathrm{Cl}\left(\mathrm{H}_{2} \mathrm{O}\right)_{4}^{+}>\mathrm{UO}_{2} \mathrm{OH}\left(\mathrm{H}_{2} \mathrm{O}\right)^{+}$. Spin-orbit CI calculations at the B3LYP and LDA optimized geometries give the same ordering as from the corresponding DFT calculations. It is found that the LDA geometries are higher energy geometries at the spin-orbit CI level of theory especially for the $\mathrm{UO}_{2} \mathrm{OH}\left(\mathrm{H}_{2} \mathrm{O}\right)^{+}$complex. The spin-orbit $\mathrm{CI}$ excitation energy to the first excited state (the fluorescent state) of the hydroxide complex, calculated at B3LYP geometries, agrees well with the experimental value. Structures of $\mathrm{UO}_{2} \mathrm{~F}_{2}$ complexes with water ligands have been optimized with DFT and the spectra were calculated with spin-orbit CI method. Trends in structures and frequencies of some actinyls (from Ac to $\mathrm{Cm}$ ) are studied with spin-orbit DFT method. Several low-lying electronic states of UO are calculated with spin-orbit CI and the ground state configurations are determined and compared with assignments from combined experimental and ligand-field studies.

Based upon our benchmarking work and comparison with experiment, we have found that LDA gives satisfactory structures and vibrational frequencies. For more accurate energetics, B3LYP is advantageous. The Stuttgart RECPS were identified as being most accurate of all available RECPs.

\section{$\underline{\text { NMR Property Calculations }}$}

In support of experimental projects at PNNL we have been computing electric-field gradient tensors (EFG) and NMR chemical shift tensors in order to help design NMR experiments for the speciation of uranyl carbonate and nitrate complexes. The NMR properties of the elements ${ }^{235} \mathrm{U}$, ${ }^{17} \mathrm{O}$ and ${ }^{14} \mathrm{C}$ in the molecule series $\mathrm{UO}_{2}{ }^{2+}, \mathrm{UO}_{2} \mathrm{CO}_{3}, \mathrm{UO}_{2}\left(\mathrm{CO}_{3}\right)^{2-}$ and $\mathrm{UO}_{2}\left(\mathrm{CO}_{3}\right)_{3}{ }^{4-}$ (figure 3 ) and the corresponding nitrates were calculated. From the calculated results it was concluded that measurements on uranium could only be done using NQR experiments. However, measurements on oxygen and carbon would be feasible and are actually done right now.

Calculations have been performed on the EFG and NMR chemical shift of ${ }^{139} \mathrm{Re},{ }^{99} \mathrm{Tc}$, and ${ }^{17} \mathrm{O}$ in an ammonium pertechnetate crystal structure. The ammonium perrhenate, which has structural 
parameters very close to the pertechnetate, has been studied extensively and nuclear quadrupole resonance data is available. Both the pertechentate and the perrhenate consist of a slightly distorted tetrahedral $\left[\mathrm{XO}_{4}\right]^{-}$unit $(\mathrm{X}=\mathrm{Tc}$ or $\mathrm{Re})$, surrounded by tetrahedral and flattened tetrahedral ammonium ions. Good agreement has been found between the calculated and experimental data.

As part of a Level VI LDRD project we have performed ab initio calculations on ${ }^{139} \mathrm{La}^{3+}$ in the $\left[\mathrm{La}(\mathrm{NO} 3)_{3}\left(\mathrm{H}_{2} \mathrm{O}\right)_{5}\right] \cdot \mathrm{H}_{2} \mathrm{O}$ crystal structure. NWChem was used to get the optimal positions for the hydrogen atoms in the experimental structure, as these atoms cannot be elucidated with X-ray experiments. Initial results show a reasonable agreement between theory and experiment but further calculations, and low-temperature experiments have to be done.

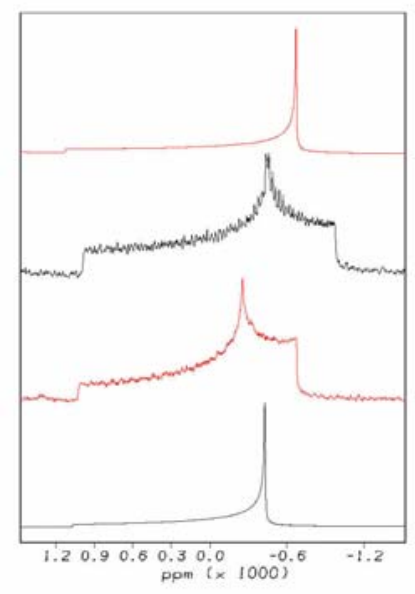

Figure 3. uranyl carbonate NMR spectra.

\section{Method and Computer Program Development}

The relativistic capabilities of NWChem have been extended considerably. An RECP-based spin-orbit-DFT module was developed allowing users to study the spin-orbit effects on molecular systems. Gradients were implemented for this approach, allowing for the optimization of geometries and the calculation of frequencies, a unique capability that is not available elsewhere. We have parallelized the fully relativistic program package MOLFDIR, which now allows us to do large-scale benchmark calculations. In N implemented within NWChem a RECP-based SO-DFT module. The spin-free one-electron Douglas-Kroll-Hess Hamiltonian has been implemented in the NWChem code, and contracted basis sets have been developed for use with this Hamiltonian. The parallel version of DIRAC has been installed and extended, and with partial funding from this project, the parallel version of ADF was made available to all MSCF users.

\section{Argonne National Laboratory}

The researchers at Argonne have been carrying out a series of calculations comparing the electronic and geometric structures of binary compounds of the actinide containing americium chloride and its lanthanide counterpart, europium chloride. These calculations are performed using a spin-orbit Configuration Interaction (SOCI) procedure made feasible for these problems by exploiting parallel processing hardware.

\section{Eloret}

Hundreds of long-running single-processor jobs were used to optimize all-electron, relativistic, correlation-consistent basis sets for most atoms in the periodic table, with an emphasis on actinides and lanthanides. Double and triple zeta quality SCF basis sets have been optimized for $\mathrm{Pa}-\mathrm{Lr}$, and correlating functions have been generated for some of these.Software development activities include the parallelization of DREAMS and implementation within NWChem of SO-RECP integrals including gradients. 


\section{The Ohio State University (Bursten, Li)}

Extensive theoretical electronic structure calculations were done on a series of unique (and, in many cases, remarkably large) actinide compounds, using ADF and NWChem. The goal of this research project is to provide theoretical support to experimentalists in the form of high-level electronic structure calculations on actinide-containing systems. We have investigated the vibrational properties of laser-ablated reaction products of $\mathrm{U}+\mathrm{CO}$ $\mathrm{Th}+\mathrm{CO}, \mathrm{Th} / \mathrm{U}+\mathrm{CO}_{2}$, and $\mathrm{An}(\mathrm{OR})_{4}(\mathrm{An}=\mathrm{Th}-\mathrm{Am} ; \mathrm{R}=\mathrm{H}, \mathrm{Me}, \mathrm{Ph}$; see figure 4 for an example). Our collaborative theoretical and experimental study of the first actinide-containing carbene compound, a triplet CThO molecule was reported in the January 10, 2000 issue of Chemical \& Engineering News, P. 26. We were able to perform theoretical electronic structure calculations on a series of unique (and, in many cases, remarkably large) actinide compounds, including $\mathrm{UF}_{6}, \mathrm{U}(\mathrm{CO})_{2}$, and $\left(\eta^{6}-\mathrm{C}_{6} \mathrm{H}_{3} \mathrm{R}_{3}\right)_{2} \mathrm{U}\left(\mathrm{R}=\mathrm{H}, \mathrm{CH}_{3},{ }^{\mathrm{t}} \mathrm{Bu}\right)$. Currently, one paper reporting the first actinide-noble gas bond has been submitted to Science magazine.

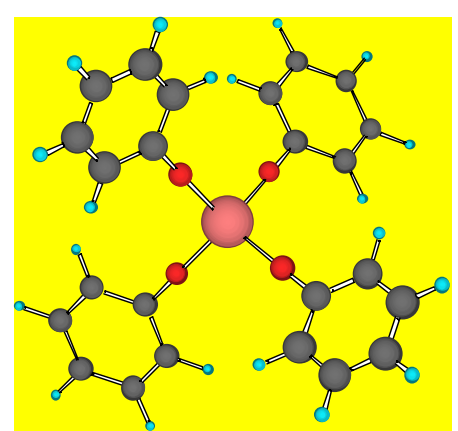

Figure 4. $\mathrm{Pu}(\mathrm{OPh})_{4}$

In order to examine the spin-orbit coupling effect on the geometries, vibrational frequencies, infrared absorption intensities, and reaction energetics, we have optimized the geometries and energies of $\mathrm{UO}_{2}{ }^{2+}, \mathrm{UF}_{6}$, and $\mathrm{UF}_{5}$ molecules using the SODFT method in NWChem. The total energies and dissociation energies for $\mathrm{UF}_{6} \rightarrow \mathrm{UF}_{5}+\mathrm{F}$ were obtained.

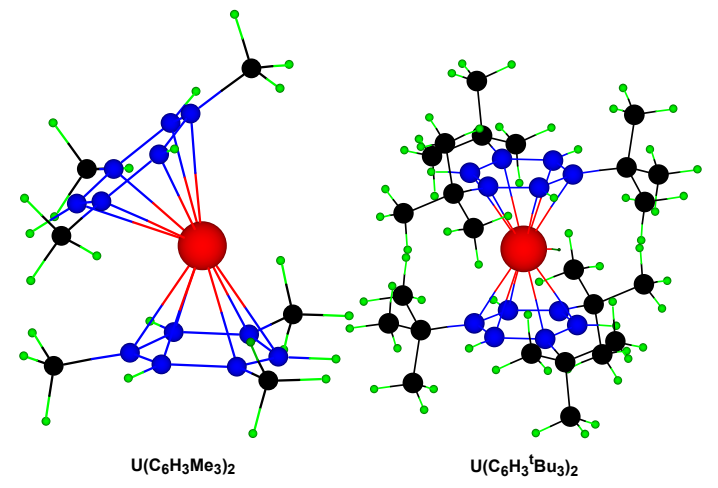

Figure 5. $U\left(\eta^{6}-1,3,5-\mathrm{C}_{6} \mathrm{H}_{3} \mathrm{R}_{3}\right)_{2}$ structures

We have shown that bis(benzene) actinide sandwich complexes, $\left(\eta^{6}-\mathrm{C}_{6} \mathrm{H}_{6}\right)_{2} \mathrm{An}(\mathrm{An}=\mathrm{Th}$ Am) strongly prefer to have bent sandwich structures, with the centroid-An-centroid angle $(\theta)$ in the range of $130-140 \mathrm{E}$. In order to assess the effects of bulky arenes, fully optimized geometry calculations were carried out for $\left(\eta^{6}-1,3,5-\right.$ $\left.\mathrm{C}_{6} \mathrm{H}_{3} \mathrm{R}_{3}\right)_{2} \mathrm{An}\left(\mathrm{An}=\mathrm{Th}, \mathrm{U}, \mathrm{Pu} ; \mathrm{R}=\mathrm{Me},{ }^{\mathrm{t}} \mathrm{Bu}\right)$ sandwich complexes, shown in figure 5 . The calculations that we report on tri-tert-butylbenzene sandwich complexes are the largest ever carried out on an actinide system.

Laser-ablated Th atoms reacting with $\mathrm{H}_{2} \mathrm{O}$ during condensation in excess argon have formed a series of interesting new compounds involving Th- $\mathrm{H}$ and $\mathrm{Th}-\mathrm{OH}$ bonds. We have determined the geometric structures and discussed the electronic structures and bonding of a series of laserablated $\mathrm{Th}+\mathrm{H}_{2} \mathrm{O}$ reaction products, including $\mathrm{HThO}, \mathrm{H}_{2} \mathrm{ThO}, \mathrm{HTh}(\mathrm{O}) \mathrm{OH}, \mathrm{HTh}(\mathrm{OH})_{3}$ and $\mathrm{OTh}(\mathrm{OH})_{2}$ species. The ground electronic states, equilibrium geometries and isotopic frequencies of possible $\mathrm{Th}+\mathrm{H}_{2} \mathrm{O}$ reaction products have been calculated. Similar calculations have been performed for the $\mathrm{U}+\mathrm{H}_{2} \mathrm{O}$ reaction products $\mathrm{H}_{2} \mathrm{UO}, \mathrm{HU}(\mathrm{O}) \mathrm{OH}, \mathrm{H}_{2} \mathrm{UO}_{2}$, and $\mathrm{H}_{2} \mathrm{U}(\mathrm{O})(\mathrm{OH})_{2}$. Our calculated results are in good agreement with the observed spectra and strongly support the identification of these novel actinide oxyhydrides from matrix infrared spectra. 
Relativistic DFT calculations have been performed on the species of CUO, U(CO), U(CO $)_{2}$, OUCCO, and $\left(\eta^{2}-\mathrm{C}_{2}\right) \mathrm{UO}_{2}$, which are generated in laser-ablated reactions between uranium atoms with $\mathrm{CO}$ molecule. These calculations provide strong support to the experimental assignments of the infrared spectra of these species. It is predicted that CUO is a linear molecule with the shortest $\mathrm{U}-\mathrm{C}$ bond yet characterized, and it has a $\mathrm{U}-\mathrm{C}$ triple bond with substantial $\mathrm{U} 5 \mathrm{f}$ character.

In order to examine the spin-orbit coupling effect on the geometries, vibrational frequencies, infrared absorption intensities, and reaction energetics, we have optimized the geometries and energies of $\mathrm{UO}_{2}{ }^{2+}, \mathrm{UF}_{6}$, and $\mathrm{UF}_{5}$ molecules using SODFT. The scalar-relativistic total energies, the vibrational frequencies, and the spin-orbit effects of various molecular properties weer obtained. The total energies and dissociation energies for the reactants and products of the reaction $\mathrm{UF}_{6} \rightarrow \mathrm{UF}_{5}+\mathrm{F}$ were calculated.

\section{Syracuse University}

The researcher at Syracuse has developed a massively parallel resolution-of-the-identity MP2 (RI-MP2) program within NWChem that is 30-times faster than the conventional approach and is capable of performing far larger calculations. The RI-MP2 method combines the "resolution of the identity" integral approximation (RI) with second-order many-body perturbation theory (MP2) to produce a "fast" version of the traditional MP2 approach which is particularly useful for calculations with large per-atom basis sets. The RI-MP2 method was used to provide "benchmark" quality results for the relative energies of tetramethoxycalix[4]arene conformers to facilitate development of more accurate parameterizations of forcefields and semiempirical methods for these systems. DFT and (RI-) MP2-level calculations in this work obtain good results for both the ordering and actual energies of the conformers compared with experimental results, while current parameterizations for the simpler methods do not perform well. In some of the largest MP2-level calculations reported to date (2460 AO basis functions/8260 fitting functions), scalability was found to be quite good from 16 to 128 nodes, and the largest RI-MP2 calculations are estimated to be 90 times faster than the corresponding exact MP2 calculations would have been.

\section{$\underline{\text { University of Toulouse }}$}

Nina Ismail-Büchner, a graduate student with Prof. Marsden, has performed a study on the molecule series $\mathrm{UX}_{2}$ and $\mathrm{UXY}\left(\mathrm{X}, \mathrm{Y}=\mathrm{O}, \mathrm{S}, \mathrm{Se}\right.$ and Te). Except for $\mathrm{UO}_{2}{ }^{2+}$, which is a strongly bound linear molecule, the other molecules in this series are found to be strongly bent and open shell systems. These bent molecules seem to form X-X (S-Te) or X-Y (O-Te) bonds.

\section{The Ohio State University (Pitzer, Wang)}

Studies of solutions containing $\mathrm{UO}_{2} \mathrm{~F}_{\mathrm{n}}{ }^{2-\mathrm{n}}$ species have shown that $\mathrm{UO}_{2} \mathrm{~F}_{2}$ luminescence is the most intense. Thus we have studied the structure and spectra of $\mathrm{UO}_{2} \mathrm{~F}_{2}$. Initially we were studying the isolated molecule, and then we added solvating water molecules, and optimized the structure to get the spectra for species in solution. The optimization work was done by DFT 
method. We studied the molecule with the addition 2,3 , and 4 waters to $\mathrm{UO}_{2} \mathrm{~F}_{2}$, with trans and cis geometry respectively. We have found that the 6-coordinate structure, hence 4 water molecules, leads to a stable structure.

\section{$\underline{\text { Stevens Institute of Technology }}$}

The COLUMBUS program was used for Spin-Orbit Configuration Interaction (SOCI) calculations for many electronic states of $\mathrm{RuO}, \mathrm{EuO}_{2}{ }^{2+}$ and $\mathrm{AmO}_{2}{ }^{2+}$. We have performed SOCI calculations using a large-core (LC) averaged relativistic effective core potential (ARECP) and the corresponding spin-orbit operator. In addition, the molecular structures of these systems were calculated with NWChem, GAMESS, GAUSSIAN 98, and COLUMBUS were used for SCF calculations with SC (small core)-ARECPs and LC-ARECPs and for all-election calculations. Comparing the results from the COLUMBUS program have been compared with the results from NWChem and GAMESS, we found that SC-ARECP results generally show better agreement with all-electron results than LC-ARECP results.

\section{$\underline{\text { List of Publications }}$}

$\underline{\text { Published }}$

Andrews, L., B. Liang, J. Li, and B. E. Bursten, Angew. Chem., Int. Ed. Engl. 39, 4565 (2000).

Andrews, L., M. Zhou, B. Liang, J. Li, and B. E. Bursten, J. Am. Chem. Soc. 122, 11440 (2000).

Bagus, P. S., R. Broer, W. A. de Jong, W. C. Nieuwpoort, F. Parmigiani, and L.Sangaletti, "Atomic Many-Body Effects for the p-shell Photo-electron Spectra of Transition Metals", Phys. Rev. Lett. 84, 2259 (2000).

Bagus, P. S., R. Broer, W. A. de Jong, W. C. Nieuwpoort, F. Parmigiani, and L.Sangaletti, Phys. Rev. Lett. 86, 3693 (2001).

Bernholdt, D. E. and R.J. Harrison, J. Chem. Phys. 109, 1593 (1998).

de Jong, W A., D. A. Dixon, G. I. Fann, R. J. Harrison, J. A. Nichols, J. Nieplocha, and T. L. Windus, and Z. Zhang, in the proceedings of the "Fourth International Conference on Supercomputing in Nuclear Applications", SNA 2000, ed. H. Kaburaki, Center for Promotion of Computational Science and Engineering, Japan Atomic Energy Research Institute, Tokyo, Japan (2000).

de Jong, W. A., R. J. Harrison, and D. A. Dixon, J. Chem. Phys. 114, 48 (2001).

de Jong, W. A., R. J. Harrison, J. A. Nichols, and D. A. Dixon, Theor. Chem. Acc. 107, 22 (2001).

Dyall, K. G., J. Chem. Phys. 109, 4201 (1998). 
Dyall, K. G., Mol. Phys. 96, 511 (1999).

Dyall, K. G., Theor. Chem. Acc. 99, 366 (1998).

Ermler, W. C. and M.M. Marino, J. Chem. Inf. Comp. Sci. 41, 77 (2001).

Feller, D., E.D. Glendening, and W.A. de Jong, J. Chem. Phys. 110, 1475 (1999)

Li J. and B. E. Bursten, In Computational Organometallic Chemistry, T. R. Cundari, Ed., Marcel Dekker: New York, 345 (2001).

Li, J. and B. E. Bursten, J. Am. Chem. Soc. 121,10243 (1999).

Li, J., B. E. Bursten, M. F. Zhou, and L. Andrews, Inorg. Chem. 40, 5448 (2001).

Matsika, S. and R.M. Pitzer, J. Phys. Chem. A. 105, 637 (2001).

Pernpointer, M., L. Visscher, W.A. de Jong, and R. Broer, J. Comp. Chem. 21, 1176 (2000).

Tilson, J. L., R. Shepard, C. Naleway, A.F. Wagner, and W.C. Ermler, J. Chem. Phys. 112, 2292 (2000).

Wang, Q. and R. M. Pitzer, J. Phys. Chem. A. 105, 8370 (2001).

Zhang, Z. and R. M. Pitzer, J. Phys. Chem. A 103, 6880 (1999).

Zhou, M. F., L. Andrews, N. Ismail, and C. Marsden, J. Phys. Chem. A. 104, 5495 (2000).

Zhou, M., A. Lester, J. Li, and B. E. Bursten, J. Am. Chem. Soc. 121, 12188 (1999).

Zhou, M., L. Andrews, J. Li, and B. E. Bursten, J. Am. Chem. Soc. 121, 9712 (1999).

Zhou, M., L. Andrews, J. Li, and B. E. Bursten, J. Am. Chem. Soc. 121, 12188 (1999).

$\underline{\text { In Press }}$

"Scalability of Correlated Electronic Structure Calculations on Parallel Computers: A Case Study of the RI-MP2 Method," David E. Bernholdt, Parallel Computing, in press.

$\underline{\text { Submitted }}$

"Parallel Computational Chemistry: an Overview of NWChem," David E. Bernholdt, in "The CRPC Handbook of Parallel Computing," ed. Jack Dongarra et al, Morgan Kauffman Publishers. 
"On the Conformational Energetics of Tetramethoxycalix[4]arene: RI-MP2 Benchmark Calculations," John B. Nicholas and David E. Bernholdt and Benjamin P. Hay, Angew. Chemie.

$\underline{\text { In Preparation }}$

"Benchmark Calculations of $\mathrm{UF}_{\mathrm{n}}$ and $\mathrm{AnF}_{6}$ ", Li, J. and Bursten, B. E. to be submitted

"Density Functional Studies of Uranyl Carbonates Using Relativistic Effective Core Potentials", J. A. Nichols, R. J. Harrison, W. A. de Jong, E. Apra, and D. A. Dixon, manuscript in preparation.

"Density Functional Studies of Uranyl Acetates Using Relativistic Effective Core Potentials", J. A. Nichols, W. A. de Jong, and D. A. Dixon, manuscript in preparation.

"Density Functional Studies of Uranyl Nitrates Using Relativistic Effective Core Potentials", J. A. Nichols, W. A. de Jong, and D. A. Dixon, manuscript in preparation.

"Density Functional Studies of Uranyl Oxyfluorides and Oxychlorides Using Relativistic Effective Core Potentials", J. A. Nichols, R. A. Kendall and D. A. Dixon, manuscript in preparation.

Hydrated Uranyl, T. Windus and Z. Zhang, manuscript in preparation.

"Accurate ab initio calculation of the ground state ${ }^{2} \Pi_{1 / 2}{ }^{2} \Pi_{3 / 2}$ spin-orbit splitting in SiF", W. A. de Jong, Z. Zhang, and R. J. Harrison, manuscript in preparation.

"Relativistic calculations on the potential energy curves of the $\mathrm{Cl}_{2}$ molecule", W. A. de Jong, S. Xantheas, and T. N. Kitsopoulos, manuscript in preparation.

"Relativistic calculations on the Electric Field Gradients and NMR Chemical Shifts of Uranyl Carbonate Complexes", W. A. de Jong and H. H. Cho, manuscript in preparation. 


\section{List of Presentations}

\section{American Chemical Society Conference August 1998}

"Bonding and bending in the actinyls", K. G. Dyall.

Computational Chemistry of Actinides Workshop III, September 1998, Berkeley Laboratory

Note: The HPCC GC3 allocations served as a resource for the HPCC (MICS/OCTR/OS) Grand Challenge program "Computational Chemistry for Nuclear Waste Characterization and Processing: Relativistic Quantum Chemistry of Actinides", which held an annual workshop. The presentations listed here were given at this workshop.

- “On Americyl and curyl”, S. Brozell.

- "On Uranyl", Z. Zhang.

- "On Neptunyl", S. Matsika.

- "On Plutonyl”, J. Blaudeau.

- "Towards a Model Chemistry for the Actinides", N. Ismail, J. L. Heully, T. Saue, J.P. Daudey, and C. J. Marsden

- "Fully relativistic calculations on uranyl", W. A. de Jong.

- "The bonding and bending in $\mathrm{UO}_{2}{ }^{2+}, \mathrm{PaO}_{2}{ }^{+}$and $\mathrm{ThO}_{2}$." K. G. Dyall.

- "Parallel SO-CI and $\mathrm{AmCl}^{2+}$, J. Tilson. "U(BH $\left.\mathrm{BH}_{4}\right)_{4}$ ", Z. Zhang. "Pseudopotential Calculations: Calculations on $\mathrm{Am}$ and $\mathrm{AmCl}^{2+}$ ", M. Seth.

- "Ionization potentials of europium and americium", C. Naleway.

- "Comparison of small and large-core ECPs", T. Windus.

- "Small- and large-core REPs with core polarization", W. Ermler.

- "Benchmarking approximate relativistic methods", K. G. Dyall.

- "RIMP2: results and gradients", D. Bernholdt.

- "MOLFDIR capabilities", W. A. de Jong.

American Chemical Society, Anaheim National Meeting, 1999, Special Symposium of the Division of Nuclear Chemistry \& Technology, entitled "Heavy Element Complexes: The Convergence of Theory and Experiment."

- "Computational approaches to actinide chemistry", D. A. Dixon, J. A. Nichols, R. J. Harrison, T.L. Windus, G. Sandrone

- "Ab initio study of uranyl complexation by various anions in solutions." Z. Zhang, R.J. Harrison, R.M. Pitzer.

- "Fully relativistic calculations on uranyl compounds as benchmark for theory and support for experiment.", W.A. de Jong, R.J. Harrison, H.M. Cho.

- "Density functional theory of actinide complexes." J.A. Nichols, T. Windus, D.A. Dixon.

- "Density functional theory of thorium complexes." T.L. Windus, D.A. Dixon.

- "Initial theoretical studies of actinide/lanthanide chemistry." A. F. Wagner, J. L. Tilson, R. Shepard, C. Naleway, M. Seth, M. Minkoff, W. C. Ermler.

- "Ab initio spin-orbit models of americium.” J. L. Tilson, W. C. Ermler, R. M. Pitzer. 
- "Ab initio studies of transition energies of actinide and lanthanide atoms." M. Seth, J. L. Tilson, C. A. Naleway, K. G. Dyall.

- "Ab initio spin-orbit configuration interaction studies on europium", C. A. Naleway, J. L. Tilson, M. Seth, R. Shepard, W. C. Ermler.

- "Theoretical studies of the structure and bonding in actinide and transactinide molecules." B. E. Bursten, J. Li, C. S. Nash, J. P. Blaudeau.

- "Relativistic density functional and ab initio theoretical studies of actinide fluorides." J. Li, B. E. Bursten.

- "Relativistic density functional study of the geometry, electronic transitions, ionization energies, and vibrational frequencies of protactinocene, $\mathrm{Pa}(\mathrm{eta}(8)-\mathrm{C} 8 \mathrm{H} 8)(2)$ ), J. Li, B. E. Bursten

- "Ab initio studies of molecules comprised of one or more heavy elements using large-core pseudopotentials.", W.C. Ermler, M. M. Marino, M. Seth.

- "The role of the $6 p$ orbital in the bending of the actinyls." K. G. Dyall

- "Ab initio study of uranyl complexation by various anions in solutions." Z. Zhang, R. J. Harrison, R. M. Pitzer.

Computational Chemistry of Actinides Workshop IV, June 1999, The Ohio State University

Note: The HPCC GC3 allocations served as a resource for the HPCC (MICS/OCTR/OS) Grand Challenge program "Computational Chemistry for Nuclear Waste Characterization and Processing: Relativistic Quantum Chemistry of Actinides", which held an annual workshop. The presentations listed here were given at this workshop.

Note: Part of the workshop was combined with an International Spectroscopy Symposium; hence presentations were accessible to attendees of both events.

- "Density Functional Theory Calculation of Excited-State Properties of Actinides." Z. Zhang and R. Harrison.

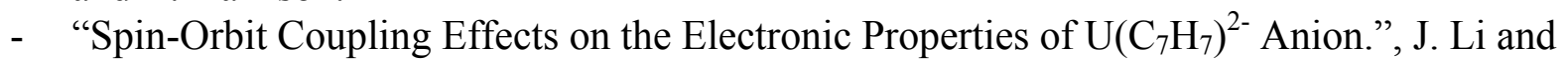
B. Bursten.

- "The Energy Levels of Uranium Ions Doped into Calcium Fluoride." S. Brozell and R. Pitzer.

- "The Energies of Lanthanide Ions, Free and Doped into Calcium Fluoride." S. Brozell and R. Pitzer.

- "Parallel RI-MP2 Energies and Gradients: Implementation and Applications." D. Bernholdt.

- "Ab Initio Calculations of the Neptunyl Ion, $\mathrm{NpO}_{2}{ }^{+2}$ and of the Dioxoneptunium(+) Ion, $\mathrm{NpO}_{2}{ }^{+}$.", S. Matsika and R. Pitzer.

- "Actinyl Ions in $\mathrm{Cs}_{2} \mathrm{UO}_{2} \mathrm{Cl}_{4}$ Crystal." S. Matsika and R. Pitzer.

- "Interactions Between Relativistic Quantum Chemists and NMR Experimentalists: Some Results." W. A. de Jong.

- "Ab Initio Relativistic Inner -Core/Outer-Core Potential Methods in Electronic-Structure Calculations." W. C. Ermler, M. Marino, and M. Seth.

- "Density Functional Theory of Actinide Complexes." J. A. Nichols, T. Windus, R. Kendall, Z. Zhang, and D. Dixon. 
- “The Chemical Properties of Europium and Americium.” C. Naleway, J. Tilson, M. Seth, R. Shepard, A. Wagner, S. Brozell, and W. C. Ermler.

- "Evolution of Relativistic Density Functional Methodologies." B. Bursten, J. Li, C. Nash, and J. Blaudeau.

- "Application of Relativistic Density Functional Theory to the Structure and Bonding of Actinide and Transactinide Molecular Systems." B. Bursten, J. Li, C. Nash, and J. Blaudeau.

American Chemical Society Conference August 2000

- Relativistic DFT studies of the reaction products of $\mathrm{An}+\mathrm{CO}$ and $\mathrm{An}+\mathrm{CO} 2(\mathrm{An}=\mathrm{Th}, \mathrm{U}) . "$ J. Li, B. E. Bursten, M. F. Zhou, L. Andrews.

$\underline{\text { Various }}$

- "Parallelization of MOLFDIR. A pathway for accessing large relativistic systems", authors: M. Pernpointer, L. Visscher, W.A. de Jong, R. Broer, W.C. Nieuwpoort at Conference of the Materials and Science Centre (University of Groningen), Vlieland (The Netherlands), 2001.

- "Relativistic computational chemistry at EMSL: Methodologies, Results, and Interaction with Experiment", authors: W. A. de Jong, R. J. Harrison, H. H. Cho, at Relativistic Effects in Heavy Elements (REHE) Conference of the European Science Foundation (ESF), Kerkrade (The Netherlands), 2001.

- "Relativistic computational chemistry at EMSL: Methodologies, Results and Interaction with Experiment, and Collaborations", W.A. de Jong, at Theoretical Chemistry group of the Free University of Amsterdam (The Netherlands), 2001.

- "Relativistic computational chemistry at EMSL: Methodologies, Results and Interaction with Experiment, and Collaborations", W. A. de Jong, at the theoretical chemistry group of the University of Groningen (The Netherlands), 2001. 


\section{List of Methods and Codes Developed}

Various codes and methodologies have been developed to enable more extensive research in this project. The developments are grouped by code:

1. NWChem.

a. Relativistic Effective Core Potentials were implemented with analytic firstderivatives.

b. Spin-orbit integrals and gradients have been implemented.

c. A spin-orbit Density Functional Theory (SO-DFT) module and its analytic gradients have been implemented, alowing for single point calculations, geometry optimizations and frequency calculations.

d. The Douglas-Kroll relativistic approximation and its gradients have been implemented.

e. Douglas-Kroll contracted basis sets have been added to the basis set library.

f. The one- and two-electron Normalized Elimination of the Small Component (NESC) relativistic approximation has been implemented with analytic derivatives.

g. NESC contracted basis sets have been added to the basis set library.

2. DREAMS. This fully relativistic code has been parallelized and ported to the MSCF IBM-SP2.

3. MOLFDIR. This fully relativistic code has been parallelized.

4. DIRAC. Extensions were made to the code to enable the use of contracted basis sets.

5. Parallel version of spin-orbit CI in COLUMBUS. 


\section{Appendix A - Full report of First Year Activities and Accomplishments}

The activities and the accomplishments are described in detail and are grouped by research institution.

\section{Pacific Northwest National Laboratory}

$\underline{\text { Uranyl-carbonates and Oxy-fluorides }}$

Thermodynamic models for aqueous complexation of tetravalent actinides ( $\mathrm{Th}, \mathrm{U}, \mathrm{Np}$, and $\mathrm{Pu}$ ) with carbonates are important because

- Carbonate is a ubiquitous ligand in ground water systems

- Carbonate can form strong aqueous complexes with tetravalent actinide species.

These complexes can increase the solubility of compounds such as tetravalent hydrous oxides that may be present in nuclear waste. There is real disagreement about the magnitude of the complexation and on the speciaton. An example of the types of systems that have been studied is: $\mathrm{K}^{+}-\mathrm{HCO}_{3}{ }^{-}-\mathrm{CO}_{3}{ }^{2-}-\mathrm{OH}^{-}-\mathrm{Ac}(\mathrm{IV})-\mathrm{H}_{2} \mathrm{O}$. One of the questions raised in these studies is for U(IV), do these species exist? The results of our calculations are presented below.

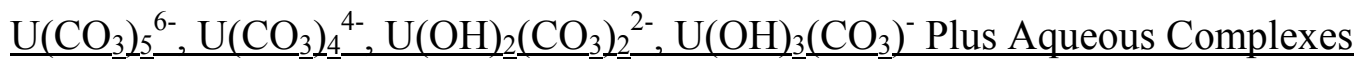

We initially started with Th(IV) and U(VI) because there are no open shell occupied f-orbitals and there are experimental data. Besides carbonate ligands, we have also been studying uranium compounds with halogens. DOE's uranium enrichment enterprise depends solely on isotopic separation by gaseous diffusion. DOE stores $\sim 560,000$ metric tons of $U_{F}$ in $\sim 46,500$ cylinders in outdoor storage yards. This $\mathrm{UF}_{6}$ is depleted in ${ }^{235} \mathrm{U}$ from isotope separation work so it is source, not waste, due to residual ${ }^{235} \mathrm{U}$ content. A leaking $\mathrm{UF}_{6}$ cylinder produces $\mathrm{UO}_{2} \mathrm{~F}_{2}$ as $\mathrm{UO}_{2} \mathrm{~F}_{2} \cdot\left(\mathrm{H}_{2} \mathrm{O}\right)_{\mathrm{m}} \cdot(\mathrm{HF})_{2}$. This can weather to give $\left[\mathrm{UO}_{2}\right]^{2+}$ in HF solution. The decomposition chemistry of $\mathrm{UF}_{6}$ includes: $\left[\mathrm{UO}_{2}\right]^{2+},\left[\mathrm{UO}_{2} \mathrm{~F}^{+}, \mathrm{UO}_{2} \mathrm{~F}_{2},\left[\mathrm{UO}_{2} \mathrm{~F}_{3}\right]^{-},\left[\mathrm{UO}_{2} \mathrm{~F}_{4}\right]^{2-}\right.$. Another issue is that fluorides and oxyfluorides of Tc are accumulating in the diffusion cascade in $\mathrm{UF}_{6}$ diffusion plants (U re-enrichment facilities). Accidental releases of ${ }^{99} \mathrm{Tc}$ into the environment are a problem at the diffusion plants and systematic releases can also occur at nuclear fuel element fabrication sites that employ re-enriched U. Based on an extensive series of benchmark calculations, we have used local density functional theory (LDFT) with large, small-core ECP basis sets on $U$ and at least polarized double zeta basis sets on the other atoms to predict structures and frequencies. Energetics have been obtained at the gradient-corrected DFT level.

We have performed extensive benchmark calculations for $\mathrm{UO}_{2}{ }^{2+}$. Our findings have been published in Theor. Chem. Acc. It has been shown that the normally used LANL ECPs lead to bent $\mathrm{UO}_{2}{ }^{2+}$. Our LDFT calculations with the small core Stuttgart ECP and corresponding valence electron basis set showed excellent agreement with the Dirac Hartree Fock/CCSD(T) results so we chose this level for the remaining calculations.

We also calculated geometries and frequencies for the $\mathrm{MO}_{2}{ }^{\mathrm{n}+}$ species for the actinides $\mathrm{M}=\mathrm{Th}$ through Am. As expected, $\mathrm{ThO}_{2}$ is bent and the calculated and experimental results are in 
reasonable agreement. The remaining molecules are linear and the bond length decreases with increasing atomic number. Surprisingly, for the $\mathrm{MO}_{2}{ }^{2+}$ species, the stretching frequencies decrease with increasing atomic number even though the bond distance is increasing. We note here that the calculations for Pu and Am were done for the high spin case.

Because of the environmental relevance of the carbonates, we have calculated the properties of a number of these species. We have compared the calculated and experimental geometry parameters for $\left[\mathrm{UO}_{2}\right]^{2+}\left[\mathrm{CO}_{3}\right]_{3}{ }^{-4}$ and $\left[\mathrm{UO}_{2}\right]_{3}\left[\mathrm{CO}_{3}\right]_{6}{ }^{-4}$. Overall the agreement with experiment is quite good. We note that the agreement is better for $\left[\mathrm{UO}_{2}\right]_{3}\left[\mathrm{CO}_{3}\right]_{6}^{-4}$, suggesting the presence of other interactions in the solid for $\left[\mathrm{UO}_{2}\right]^{2+}\left[\mathrm{CO}_{3}\right]_{3}^{-4}$. This is consistent with the uranyl vibrational frequencies we calculated. The calculated binding energies for the uranyl-carbonate species show that we expect all forms of the carbonates that we calculated to be stable. A manuscript describing our results is currently in preparation.

The geometry parameters and vibrational modes for fluorinated uranium compounds $\left[\mathrm{UO}_{2} \mathrm{~F}^{+}\right.$, $\mathrm{UO}_{2} \mathrm{~F}_{2},\left[\mathrm{UO}_{2} \mathrm{~F}_{3}\right],\left[\mathrm{UO}_{2} \mathrm{~F}_{4}\right]^{2-}, \mathrm{UOF}_{4},\left[\mathrm{UOF}_{5}\right]^{2-}$, and $\mathrm{UF}_{6}$ have been calculated. For $\mathrm{UF}_{6}$, where the experimental value is known, the agreement is excellent. The bond distances show the expected trends in terms of formal charge on the uranium and the overall charge on the complex. The vibrational modes for $\mathrm{UF}_{6}$ also show excellent agreement with experiment. In addition the vibrational frequencies for $\mathrm{UO}_{2} \mathrm{~F}_{2}$ are found to be in good agreement with the experimental results.

\section{$\underline{\text { Fluoride Affinities }}$}

The ability of a species to bind [F] $]^{-}$is the fluoride affinity (FA) and is defined like a proton affinity as the negative of the enthalpy change of Reaction (1)

$$
\mathrm{A}+[\mathrm{F}]----->[\mathrm{AF}]^{-}
$$

Because of the difficulty in calculating the electron affinity of fluorine, we calculate relative fluorine affinities as shown in Reaction (2).

$$
[\mathrm{AF}]^{-}+\mathrm{B}---->\mathrm{A}+[\mathrm{BF}]^{-}
$$

Given FA(A), then FA(B) can be calculated. We have chosen $\mathrm{FA}\left(\mathrm{COF}_{2}\right)$ as the standard. The $\mathrm{FA}\left(\mathrm{COF}_{2}\right)$ is $49.9 \mathrm{kcal} / \mathrm{mol}$ based on the revised value of $\mathrm{FA}(\mathrm{HF})$. Given the fluoride affinity of a molecule in $\mathrm{kcal} / \mathrm{mol}$, we can convert it to a Lewis acidity scale (the $\mathrm{pF}$ scale) by dividing by 10 . The $\mathrm{pF}$ scale we calculated shows that the uranium oxyfluorides are strong $\mathrm{F}^{-}$acceptors and are thus expected to be strong Lewis acids, on the order of $\mathrm{AsF}_{5}$. This means that they will be very reactive. This is the first quanitification of the Lewis acidity of these species.

\section{Addition of Water to Uranyl}

We have explored the addition of water to $\mathrm{UO}_{2}{ }^{2+}$ with the B3LYP and LDA levels of Density Functional Theory (DFT) and several different Effective Core Potentials (ECPs) and orbital basis sets to access structures, vibrational frequencies, bonding energies and the number of water 
molecules in the first solvation shell. Results have been obtained for 1-5 waters and for 15 waters. Investigations are ongoing for the 6 water case. This case has been difficult since the water does not want to be in the first solvation shell (in agreement with experiment) and the surface is relatively flat for the position of the extra water.

Several conformers of these $\mathrm{UO}_{2}{ }^{2+}\left(\mathrm{H}_{2} \mathrm{O}\right)_{\mathrm{n}}$ systems have been examined with several of them being transition states for rotation of the waters. For example, in the one water system, the

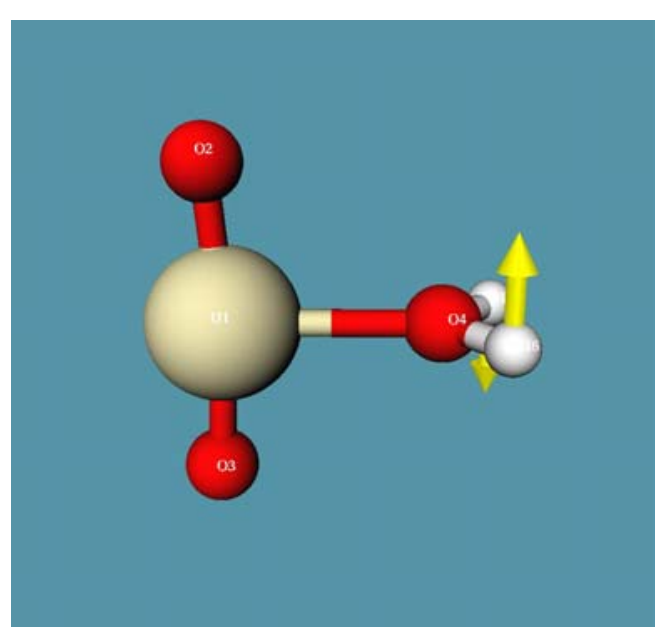

Figure A.1. $\mathrm{UO}_{2}{ }^{2+} \mathrm{H}_{2} \mathrm{O}$ conformation. following conformation, shown in figure A.1, is found in which the water wants to rotate to align with the O-U$\mathrm{O}$ axis of the uranyl. The binding energies of the waters are also of interest to elucidate the nature of the wateruranyl interaction. They also are important with respect to other ligand binding energies by aiding in the determination of the thermodynamics of the uranyl in solution. For example, as water ligands are sequentially added to the uranyl, the binding energy decreases significantly. We have obtained extensive results for the $\Delta \mathrm{E}$, which is the potential energy difference for the reaction $\mathrm{UO}_{2}{ }^{2+}\left(\mathrm{H}_{2} \mathrm{O}\right)_{\mathrm{n}} \Leftrightarrow \mathrm{UO}_{2}{ }^{2+}\left(\mathrm{H}_{2} \mathrm{O}\right)_{\mathrm{n}-1}+\mathrm{H}_{2} \mathrm{O}$, and $\Delta \mathrm{H}$, which is the same reaction including zero-point energy. The results are obtained using B3LYP, Stuttgart ECPs on $\mathrm{U}$ and $\mathrm{O}$ and TZVP (DFT orbitals) on $\mathrm{H}$.

The information gained through this study is being used to create potentials to be used in future molecular dynamics simulations. A paper is in preparation concerning this work.

In addition to the water with uranyl studies, water with thorium(IV) is also being examined with B3LYP functionals and Stuttgart small core ECPs on Th and TZVP (DFT orbitals) on O and H. These investigations are proving to be more difficult since the water with the bare ion have many different minima on the surface. Examination of 1-8 waters has been undertaken and results are still too preliminary for conclusions to be drawn.

As another callibration study, ThO2, thoranyl, is being examined with many different DFT potentials, ECPs and orbital basis sets. The geometries and frequencies are being compared to Dirac Hartree-Fock (DHF) calculations and traditional non-relativistic correlated methods. Thoranyl, unlike uranyl, is a bent molecule and many of the different combinations of functionals and ECPs do not give good results in comparison to the DHF calculations. The combination that appears to produce the best results is B3LYP with the Stuttgardt small core ECP for Th and the TZVP (DFT orbital) basis sets for O. The final calculation of the CCSD(T) DHF structure is currently underway to provide a correlated, relativistic calculation to compare with. A paper concerning this work is currently in preparation. Uranyl Nitrates and Acetates

Halides and nitrates of actinides are important due to their presence in tank waste. Acetates serve as a model for issosccharinic acid, which is a decay product of cellulose and other organic molecules. For these reasons we have examined the binding, structure and vibrational 
frequencies of nitrates and acetates of uranyl. The calculation parameters (basis set, DFT exchange correlation potential, RECP) were chosen to be consistent with the work on carbonates and hydrates so that a completely consistent set of results are obtained. The data is still being analyzed, but here is some of the raw data which already illustrates several interesting trends.

\section{$\underline{\text { Fully relativistic computational studies on actinide molecules }}$}

The work that was done can be split into two main categories, the calculation of various properties of actinide molecules using fully relativistic methods and the further development of (relativistic) quantum chemistry codes. For the calculations the fully relativistic program package MOLFDIR (and some modules of DIRAC) was used. A list of computational studies on actinide molecules that have been performed are given below.

Benchmark calculations have been performed on the $\left[\mathrm{UO}_{2}\right]^{2+}$ molecule obtaining the equilibrium bond length, symmetric, asymmetric stretch and bending frequencies at the Dirac-Hartree-Fock (DHF), MP2, CCSD and CCSD(T) level of theory using the MOLFDIR program package. These results are now used within and outside PNNL as benchmark for approximate relativistic methods.

The excited states of uranyl (in $\mathrm{Cs}_{2} \mathrm{UO}_{2} \mathrm{Cl}_{4}$ ) have been modeled using the free $\left[\mathrm{UO}_{2}\right]^{2+}$ ion and the $\left[\mathrm{UO}_{2} \mathrm{Cl}_{4}\right]^{2-}$ cluster. The calculated relative spectrum calculated with the $\left[\mathrm{UO}_{2} \mathrm{Cl}_{4}\right]^{2-}$ cluster was found to be in good agreement with experimental findings (see figure A.2). Similar calculations are currently performed for the plutonyl ion.

In order to be able to study larger molecules and to use more extended basis sets the relativistic

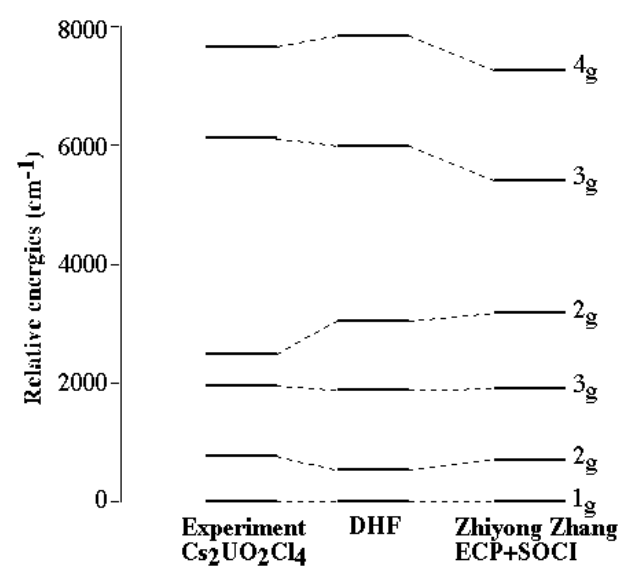

Figure A.2. Experimental spectrum vs. calculated $\mathrm{Cs}_{2} \mathrm{UO}_{2} \mathrm{Cl}_{4}$ spectra quantum chemistry codes required improvement. To take full benefit of the parallel computer environments at PNNL and at NERSC a parallel version of the twoelectron computation and Dirac-Hartree-Fock process, both running under MPI, have been developed within the MOLFDIR program package.

In the future the influence of correlation effects on the EFG values of uranium and oxygen in the uranyl ion complexes will be studied using the parallel DIRAC code. Also, the NMR chemical shifts of the uranyl complexes will be studied, which will provide the experimentalists with additional information. Besides the uranyl complexes some lanthanide complexes will be studied. The computational studies on the excited states of actinyl complexes will be continued.

The computed relative spectrum (DHF results) of the lowest 8 excited states of the uranyl ion, modeled using the $\left[\mathrm{UO}_{2} \mathrm{Cl}_{4}\right]^{2-}$ cluster, are compared with experimental data and calculated results of Dr. Zhang (DHF = Dirac-Hartree-Fock, $\mathrm{ECP}+\mathrm{SOCI}=$ Effective Core Potential followed by Spin-Orbit Configuration Interaction). 


\section{Speciation of Aqueous Uranyl By Laser Spectroscopy}

Current investigation is mainly focused on ab initio calculation of uranyl compounds in water. Compounds studied include uranyl $\left(\mathrm{UO}_{2}{ }^{2+}\right)$ and several uranyl-anion complexes $\left(\mathrm{UO}_{2} \mathrm{OH}^{+}\right.$, $\mathrm{UO}_{2} \mathrm{~F}^{+}$and $\mathrm{UO}_{2} \mathrm{Cl}^{+}$). Understanding of the interaction between uranyl and different ligands found in natural aqueous environment is important to illustrate the fate and transport of uranyl compounds. Trends in the structure and vibrational frequencies of these compounds with different number of complexed waters, as well as their thermodynamic properties, both in their ground- and excited-states are studied. Also studied are the transition energies from the ground state to the first excited state, the fluorescence from which are used to identify trace amount of uranyl complexes. Structures and frequencies are calculated using DFT methods with LDA and B3LYP functionals and transition energies are calculated using spin-orbit CI method. So far we have finished the structure and frequency calculations and the transition energy calculation is still in progress. The current work will be extended to include the solvation effects on hydrated uranyl compounds. The speciation of these compounds at mineral surfaces will also be modeled.

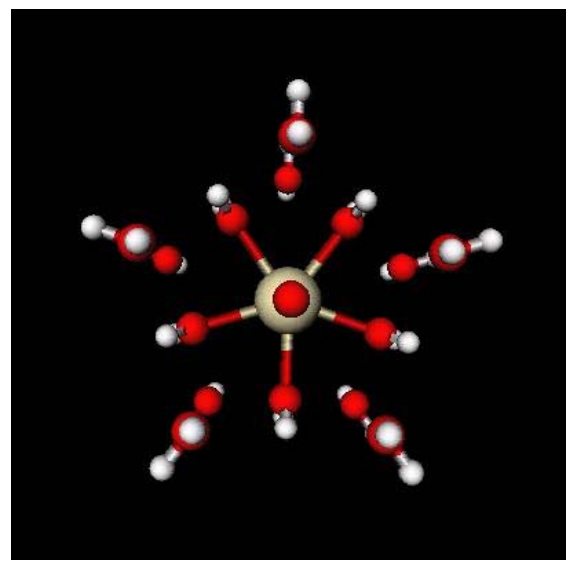

Figure A.3. $\mathrm{UO}_{2}\left(\mathrm{H}_{2} \mathrm{O}\right)_{5}{ }^{2+}$ in a solvation shell of 10 waters.

We have calculated the ground state structures, frequencies and binding energies of $\mathrm{UO}_{2}\left(\mathrm{H}_{2} \mathrm{O}\right)_{n}{ }^{2+}(\mathrm{n}=1,5)$, $\mathrm{UO}_{2}(\mathrm{OH})\left(\mathrm{H}_{2} \mathrm{O}\right)_{\mathrm{n}}{ }^{+}(\mathrm{n}=1,4), \mathrm{UO}_{2} \mathrm{~F}\left(\mathrm{H}_{2} \mathrm{O}\right)_{\mathrm{n}}{ }^{+}(\mathrm{n}=1,4)$, and $\mathrm{UO}_{2} \mathrm{Cl}\left(\mathrm{H}_{2} \mathrm{O}\right)_{\mathrm{n}}{ }^{+}(\mathrm{n}=1,4)$. For uranyl-water complexes it is found that the most stable structure has five waters bonded to the uranyl ion in the first solvation shell (figure A.3).

Calculations with six waters are also carried out and several minima are identified to understand the interaction of the first solvation shell with surrounding waters in the solution. For that purpose calculations with ten additional waters, occupying positions below and above the equatorial plane, are also carried out and notable changes in the symmetrical stretch frequencies are observed.

We also obtained some results for the excited states of these aforementioned molecules. $\mathrm{UO}_{2} \mathrm{Cl}_{4}{ }^{2-}$ is one of the uranyl compounds with the most detailed experimental spectroscopic information and can be used as a test case to gauge the performance of the employed methods of calculation. Our calculation also identified the first ungrade transition as due to ligand (Chloride) to uranyl charge transfer, as found experimentally.

For actinide compounds with open-shell electrons the spin-orbit effect would be expected to be important in determining the structure and frequencies. To this end a spin-orbit DFT code capable of geometry optimization is being developed and currently the energy code has already been implemented. A major effort to parallel the current SO GUGA CI program is also undertaken.

\section{Accurate Determination of the Binding Energies of the First Few Water Clusters}

We have obtained accurate binding energies for the first few $(n=3-6)$ water clusters using the family if correlation consistent basis sets. Estimates of the MP2 complete basis set limits are:- 
$15.8 \mathrm{kcal} / \mathrm{mol}$ (cyclic trimer), $-27.6 \mathrm{kcal} / \mathrm{mol}$ (cyclic tetramer), $-36.3 \mathrm{kcal} / \mathrm{mol}$ (cyclic pentamer), $-44.8 \mathrm{kcal} / \mathrm{mol}$ (cyclic hexamer), $-45.8 \mathrm{kcal} / \mathrm{mol}$ (cage hexamer) and $-45.9 \mathrm{kcal} / \mathrm{mol}$ (prism hexamer). The effects of additional correlation estimated at the $\operatorname{CCSD}(\mathrm{T})$ level of theory indicate that the MP2/CBS values are accurate to within $0.2 \mathrm{kcal} / \mathrm{mol}$ or less.

The parametrization of interaction potentials for water is commonly performed using available data from a variety of environments ranging from clusters to liquid water and ice. The results for water clusters offer the advantage of probing the fundamental interactions at the molecular level and therefore systematically identifying the physical terms necessary to describe hydrogen bonding. However, no direct experimental measurements have been performed to date for the interaction energies of even small clusters such as the water dimer let alone liquid water and/or ice. Most energetic information that is used in the parameterization of interaction potentials comes either directly from calculations or indirectly from measurements of thermodynamic quantities such as the heat of vaporization/sublimation for the various water/ice phases.

First principles electronic calculations offer the advantage of providing this much-needed energetic information that is the cornerstone in the benchmarking and parametrization of interaction potentials for water. The issue of accuracy is of outmost importance since, for instance, numbers within "chemical accuracy" $(1 \mathrm{kcal} / \mathrm{mol})$ for the binding energies of small water clusters are needed in order to ensure transferability for larger systems such as bulk water and ice and produce meaningful results. This range typically represents a small ( 1-2\%) percentage of the cluster binding energies. However, the computational cost scales theoretically between $\mathrm{N}^{3}$ to $\mathrm{N}^{5}, \mathrm{~N}$ being proportional to the size of the system. For the water hexamer, for example, in order to tighten the accuracy of the computed binding energies from $10 \%$ to $1 \%$ requires a 10,000x increase in the computational cost. These calculations are currently impossible on conventional computers using serial architectures.

We have performed full geometry optimizations of the clusters water trimer through the various hexamer isomers (cage, prism, book, cyclic) at the MP2 level of theory with the aug-cc-pVTZ basis set. Single point energies were computed at these optimized geometries with the larger aug-cc-pVQZ and aug-cc-pV5Z sets at the MP2 level of theory. All calculations were performed using the NWCHEM suite of codes. The largest calculation for the water hexamer [1722 total contractions] was run on 128 nodes of the IBM SP2 at EMSL. Basis set superposition error (BSSE) corrections were estimated using the function counterpoise method. Even with the largest basis set used in this study (aug-cc-pV5Z) these amount to $\sim 1.0 \mathrm{kcal} / \mathrm{mol}$ for the various hexamer isomers. Using the binding energies obtained with the double- through the quintuplezeta basis sets we estimate the following MP2 complete basis set (CBS) limits: $-15.8 \mathrm{kcal} / \mathrm{mol}$ (cyclic trimer), $-27.6 \mathrm{kcal} / \mathrm{mol}$ (cyclic tetramer), $-36.3 \mathrm{kcal} / \mathrm{mol}$ (cyclic pentamer), $-44.8 \mathrm{kcal} / \mathrm{mol}$ (cyclic hexamer), $-45.8 \mathrm{kcal} / \mathrm{mol}$ (cage hexamer) and $-45.9 \mathrm{kcal} / \mathrm{mol}$ (prism hexamer). The effect of additional correlation estimated at the $\operatorname{CCSD}(\mathrm{T})$ level of theory for the trimer and tetramer clusters suggests that the MP2 values are accurate to within $0.2 \mathrm{kcal} / \mathrm{mol}$ or less for the total binding energies. 


\section{$\underline{\text { Argonne National Laboratory }}$}

\section{The Electronic Structure of Americium and Europium Chloride}

At Argonne, we have been carrying out a series of calculations comparing the electronic and

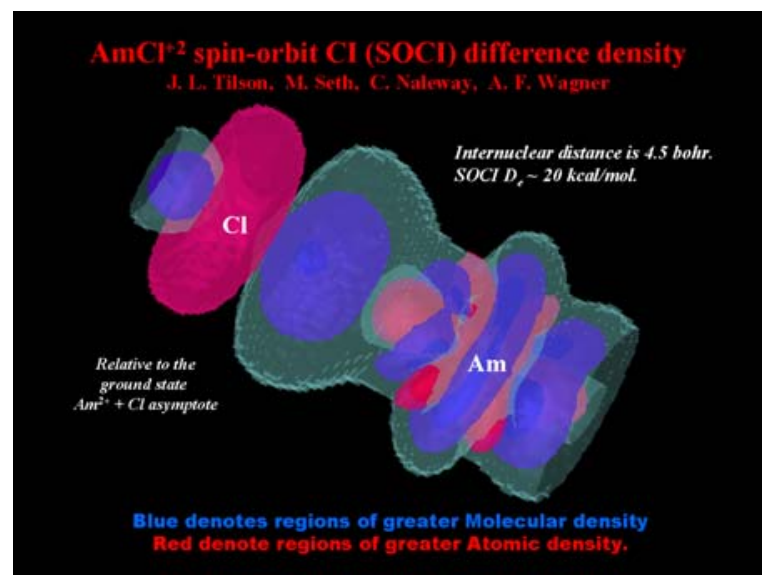

Figure A.4. Electron density of $\mathrm{AmCl}^{2+}$. geometric structures of binary compounds of the actinide containing americium chloride and its lanthanide counterpart, europium chloride. These calculations are performed using a spin-orbit Configuration Interaction (SOCI) procedure made feasible for these problems by exploiting parallel processing hardware. The large computing requirements reflect the large number of openshell $\mathrm{f}$ electrons in Am and Eu. We have adapted a sequential SOCI code to parallel computations and have run this code on hundreds of processors on the MPP1 SP computer in the EMSL facility at PNNL and at the T3E facility at NERSC. Among the results of these calculations are the following:

- The first ionization potential of Am and Eu can be calculated to within about $.25-.50 \mathrm{eV}$ of reliable experiments. The calculated values for the second and third ionization potentials are likely to have similar errors and are probably superior in accuracy to the available, indirect experimental values.

- The f-f splitting in Eu are accurate within $100-200 \mathrm{~cm}^{-1}$ compared to experimental values, which are slightly perturbed by crystal field effects. The f-f splittings in Am deviate from experiment by many hundreds of $\mathrm{cm}^{-1}$. The origin of this disagreement is the pseudopotentials. The two most rigorous pseudopotentials available (those due to Nash, Bursten, and Ermler and those due to Dolg's group) both have large, though different, deviations from experiment in SOCI calculations at the single and double excitation level. These results argue for a new generation of pseudopotentials.

- $\mathrm{AmCl}^{2+}$ and $\mathrm{EuCl}^{2+}$ potential curves have an inner and outer well where the inner well is due at least in part to charge exchange. $f$-f spectroscopy does change with chemical bonding of the chlorine but further work now in progress is needed to understand this effect. The electron density of $\mathrm{AmCl}^{2+}$ is shown in figure A.4.

\section{The Ohio State University (Bursten and Li)}

Benchmark Calculations of $\mathrm{UF}_{\underline{\underline{n}}}$ and $\mathrm{AnF}_{\underline{6}}$

Using LDA and PW91 functionals, we have calculated the geometries and vibrational frequencies and intensities of the infrared and Raman of $\mathrm{UF}_{n}(\mathrm{n}=1-6)$ and $\mathrm{AnF}_{6}(\mathrm{An}=\mathrm{U}, \mathrm{Np}$, $\mathrm{Pu}, \mathrm{Am})$. It has been shown that the spin-orbit effects are negligible for the structures and vibrational frequencies of the ground states of these molecules. Our calculated PW91 excited energies are in very good accord with those from spin-orbit CI calculations as well as the 
available experimental data. Benchmark calculations using NWChem and ADF have provided a comparison of the STO- and GTO-based DFT methods.

\section{$\underline{\text { Bis(arene) Actinide Sandwich Complexes }}$}

Using relativistic density functional theory (DFT), we have shown that bis(benzene) actinide sandwich complexes, $\left(\eta^{6}-\mathrm{C}_{6} \mathrm{H}_{6}\right)_{2} \mathrm{An}(\mathrm{An}=\mathrm{Th}-\mathrm{Am})$ strongly prefer to have bent sandwich structures, with the centroid-An-centroid angle $(\theta)$ in the range of $130-140 \mathrm{E}$. In order to assess the effects of bulky arenes, fully optimized geometry calculations were carried out for $\left(\eta^{6}-1,3,5\right.$ $\left.\mathrm{C}_{6} \mathrm{H}_{3} \mathrm{R}_{3}\right)_{2} \mathrm{An}\left(\mathrm{An}=\mathrm{Th}, \mathrm{U}, \mathrm{Pu} ; \mathrm{R}=\mathrm{Me},{ }^{\mathrm{t}} \mathrm{Bu}\right)$ sandwich complexes. For $\mathrm{R}=\mathrm{Me}$, the complexes still prefer to be bent with $\theta$ of about $140 \mathrm{E}$. For $\mathrm{R}={ }^{\mathrm{t}} \mathrm{Bu}$, the steric repulsion is great enough that the complexes become linear $(\theta=180 \mathrm{E})$, much like the experimentally determined structure of $\left(\eta^{6}-1,3,5-\mathrm{C}_{6} \mathrm{H}_{3}{ }^{t} \mathrm{Bu}_{3}\right)_{2} \mathrm{Gd}$. The calculations that we report on tri-tert-butyl-benzene sandwich complexes are the largest ever carried out on an actinide system (For $\left(\eta^{6}-1,3,5-\mathrm{C}_{6} \mathrm{H}_{3}{ }^{\mathrm{t}} \mathrm{Bu}_{3}\right)_{2} \mathrm{U}$, shown in figure A.4, there are 97 atoms, 218 valence electrons, 817 uncontracted valence basis function and the optimizations were carried out without symmetry restriction).

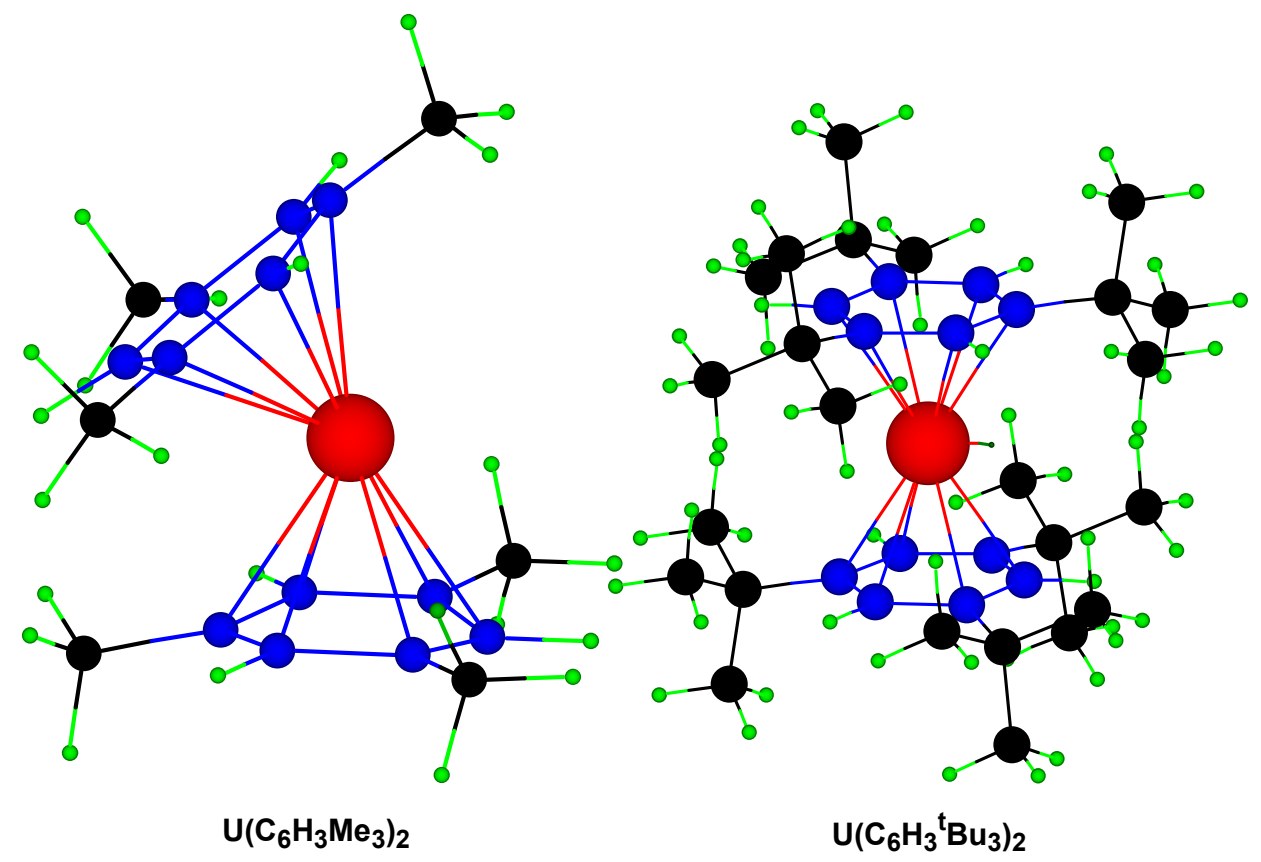

Figure A.4. Optimized $U\left(\eta^{6}-1,3,5-\mathrm{C}_{6} \mathrm{H}_{3} \mathrm{R}_{3}\right)_{2}$ structures

\section{$\underline{\text { Uranium Carbonyls }}$}

Relativistic density functional theoretical calculations have been performed on the species of $\mathrm{CUO}, \mathrm{U}(\mathrm{CO}), \mathrm{U}(\mathrm{CO})_{2}$, OUCCO, and $\left(\eta^{2}-\mathrm{C}_{2}\right) \mathrm{UO}_{2}$, which are generated in laser-ablated reactions between uranium atoms with $\mathrm{CO}$ molecules. These calculations lend strong support to the experimental assignments of the infrared spectra of these species. It is predicted that $\mathrm{CUO}$ is a linear molecule with the shortest $\mathrm{U}-\mathrm{C}$ bond yet characterized, and it has a $\mathrm{U}-\mathrm{C}$ triple bond with 
substantial $\mathrm{U} 5 \mathrm{f}$ character. The theoretical analysis also finds that a distorted tetrahedral geometry of $\left(\mathrm{C}_{2}\right) \mathrm{UO}_{2}$ lies much lower in energy than either the bent/linear OUCCO structures or the $\mathrm{U}(\mathrm{CO})_{2}$ uranium dicarbonyl.

\section{Syracuse University}

This work was done in a collaborative effort between Syracuse University and PNNL.

\section{$\underline{\text { RI-MP2 and Selectively Binding of Alkali Metal Atoms by Calixarenes }}$}

High quality calculations have been carried out on tetramethoxycalix[4]arene (TMC) molecule using the RI-MP2 module of NWChem. Chemically, the TMC system is of interest as a computationally tractable model for calixarene systems that are being studied in DOE and elsewhere for their ability to selectively bind alkali metal atoms. An important application of this capability could be the separation from cesium from aqueous solutions containing large amounts of sodium. Unfortunately, various computational approaches (forcefield, semiempirical, and density functional theory) give varying results for things like the relative energies of the four TMC conformations. It is important to understand what level of calculation is sufficient to model such systems accurately, and for that it is necessary to have trustworthy high-quality results to compare with.

A series of calculations were carried out with cc-pVDZ, cc-pVTZ and aug-cc-pVTZ' basis sets (the latter having the augmentation only on the heavy atoms) at the MP2 level to provide the needed reference information. Due to the size of the calculations $(700,1740$, and 2460 AO basis functions respectively), the approximate RI-MP2 method was used for most calculations, with selected exact MP2 calculations at the DZ and TZ levels to check the performance of the RI approximation. The results reveal that DFT calculations do correctly order the relative energies of the conformations, but simpler methods are not reliable. The calculations also demonstrated the utility of the RI-MP2 approach for large molecules, running 14 and 32 times faster than the exact MP2 calculations for the DZ and TZ levels. No exact calculations were performed at the aug-cc-pVTZ' level, but extrapolations suggest that the RI-MP2 would be roughly 47 times faster. We believe that the 2460 basis function RI-MP2 calculations are among the largest MP2quality calculations, which have ever been reported in the literature.

As the parallel scalability of the RI-MP2 had not yet been studied on the IBM SP system, nor for a molecule of this size, we also took the opportunity to thoroughly examine this aspect of the method. The studies revealed that all aspects of the code scale well from at least 16 to 128 processors, and that significantly larger calculation with this method should be quite feasible on a system like the MSCF's MP. 


\section{Appendix B - Full Report of Second Year Activities and Accomplishments}

The activities and the accomplishments are described in detail and are grouped by research institution.

\section{Pacific Northwest National Laboratory}

Douglas-Kroll in NWChem: Parallel Energy and Gradient Calculations, and Douglas-Kroll Contracted Basis Sets

The spin-free one-electron Douglas-Kroll-Hess (DKH) Hamiltonian has been implemented in the parallel NWChem computational chemistry code, an EMSL product. To allow for geometry optimizations and frequency calculations the DKH gradient integrals have been implemented. To avoid the calculation of the complex DKH gradient integrals we have implemented an efficient and accurate mixed analytical/numerical gradient method. The use of standard non-relativistic contracted basis set can produce erroneous results for elements beyond the first row elements. Therefore, the cc-pVXZ (X = D, T, Q, 5) series of basis sets for the H, He, B - Ne, Al - Ar, and $\mathrm{Ga}-\mathrm{Br}$ elements has been recontracted using the DKH Hamiltonian, thereby incorporating the relativistic effects in the contraction coefficients.

Relativistic Calculations on the Electric Field Gradients and NMR Chemical Shifts of Uranyl Carbonate Complexes

A possible approach for the speciation of actinide complexes in soils, groundwater and in waste tanks at DOE sites is the use of Nuclear Magnetic Resonance (NMR) techniques. The signal from a NMR measurement is element and bond specific and, hence, is therefore an excellent tool for speciation. No NMR experiments have been performed on the actinide elements in complexes. Some experiments have measured the NMR signals of the lighter elements (like oxygen and carbon) surrounding the actinides. In order to do experiments on actinide elements so-called "hot" isotopes have to be used. To get some insight in the possible outcome of NMR experiments on actinide elements and their surrounding (lighter) elements, ab initio relativistic theoretical calculations have been performed. The NMR properties of the elements ${ }^{235} \mathrm{U},{ }^{17} \mathrm{O}$ and ${ }^{14} \mathrm{C}$ in the molecule series $\mathrm{UO}_{2}{ }^{2+}, \mathrm{UO}_{2} \mathrm{CO}_{3}, \mathrm{UO}_{2}\left(\mathrm{CO}_{3}\right)^{2-}$ and $\mathrm{UO}_{2}\left(\mathrm{CO}_{3}\right)_{3}{ }^{4-}$ were calculated using various computational packages available on the NWMPP1 at EMSL. These calculated properties were then used to produce simulated NMR spectra based on the available experimental settings at EMSL. The calculated NMR properties are in good agreement with the limited experimental NMR data available for the elements oxygen and carbon. Using the computed data a simulated NMR spectrum for ${ }^{17} \mathrm{O}$ in the various molecules has been generated. The spectrum is shown in the Figure B.1. 

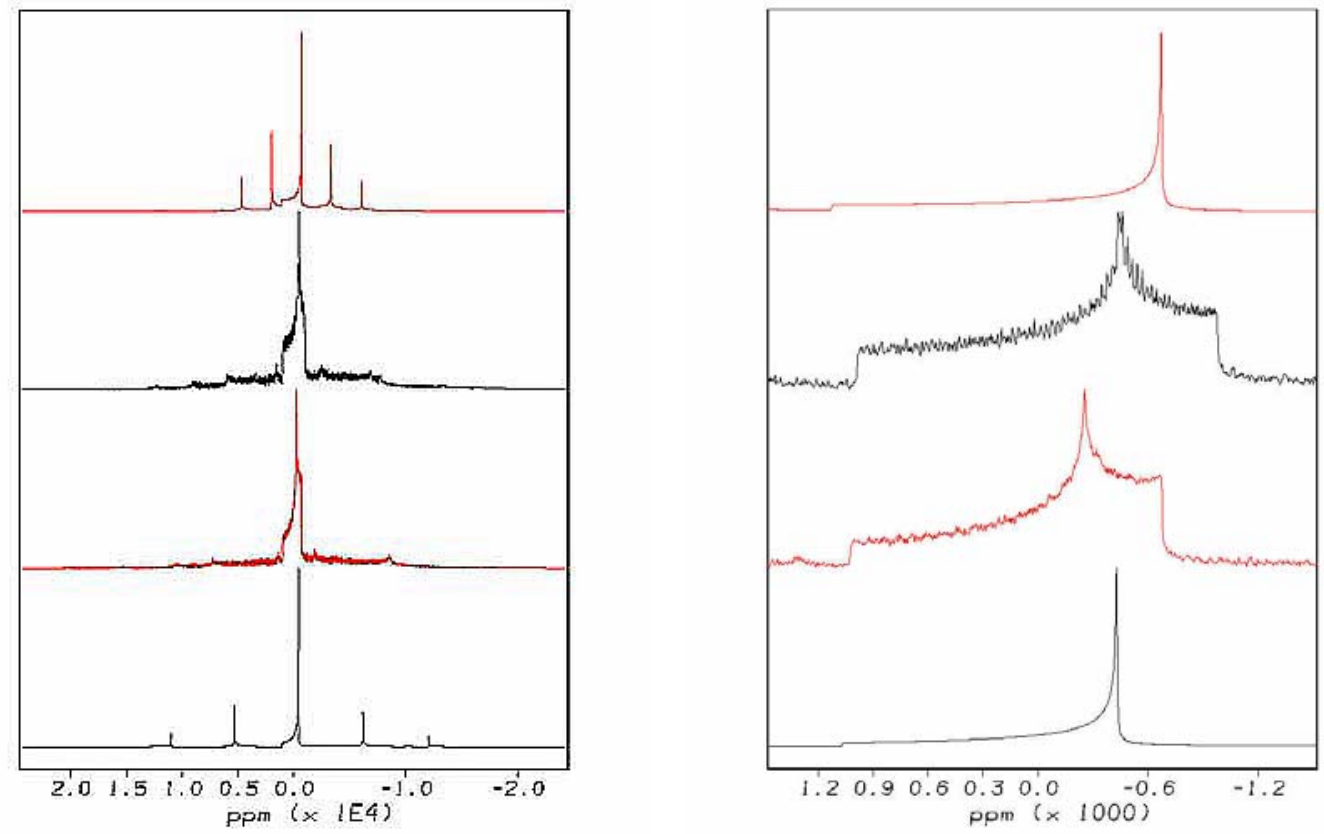

Figure B.1. Simulated NMR spectra for the ${ }^{17} \mathrm{O}$ of the uranyl unit in, from top to bottom, $\mathrm{UO}_{2}{ }^{2+}$, $\mathrm{UO}_{2} \mathrm{CO}_{3}, \mathrm{UO}_{2}\left(\mathrm{CO}_{3}\right)_{2}{ }^{2-}$ and $\mathrm{UO}_{2}\left(\mathrm{CO}_{3}\right)_{3}{ }^{4-}$ based on calculated electric field gradients, shieldings and their anisotropy. On the left the spectra for all 5 possible transitions are shown. On the right only the central $1 / 2 \leftrightarrow 1 / 2$ transition is shown on a different $\mathrm{x}$-axis scale. The spectra were calculated assuming a field of 7.04 Tesla. The relative intensities between the complexes are not on scale, the $\mathrm{UO}_{2} \mathrm{CO}_{3}$, $\mathrm{UO}_{2}\left(\mathrm{CO}_{3}\right)_{2}{ }^{2-}$ have lower intensities relative to $\mathrm{UO}_{2}{ }^{2+}$ and $\mathrm{UO}_{2}\left(\mathrm{CO}_{3}\right)_{3}{ }^{4-}$.

From the calculated results it was concluded that measurements on uranium, and most of the other important actinides, would be extremely difficult or even impossible to do. The calculated results suggested, however, that Nuclear Quadrupole Resonance (NQR) could be used to probe the actinide element in the complexes. Based on the theoretical results the experiments at EMSL will focus on the measurement of the NMR signals of oxygen and carbon in actinide complexes.

\section{$\underline{\text { Accurate Ab Initio Calculation of the Ground State }{ }^{2} \Pi_{1 / 2}-{ }^{2} \Pi_{3 / 2}}$ Spin-Orbit Splitting in SiF}

Experimentalists have been able to (very accurately) resolve the potential energy curves of the ${ }^{2} \Pi_{1 / 2}$ and ${ }^{2} \Pi_{3 / 2}$ ground states in SiF close to the equilibrium bond length. As a result they were able to obtain a ${ }^{2} \Pi_{1 / 2}{ }^{2} \Pi_{3 / 2}$ spin-orbit splitting curve. Fully relativistic calculations have been performed using the MOLFDIR program package. The calculated results, shown in figure B.2 together with the experimental results, agree to around $1 \mathrm{~cm}^{-1}$ with the experimental data, an error of less then $1 \%$. 


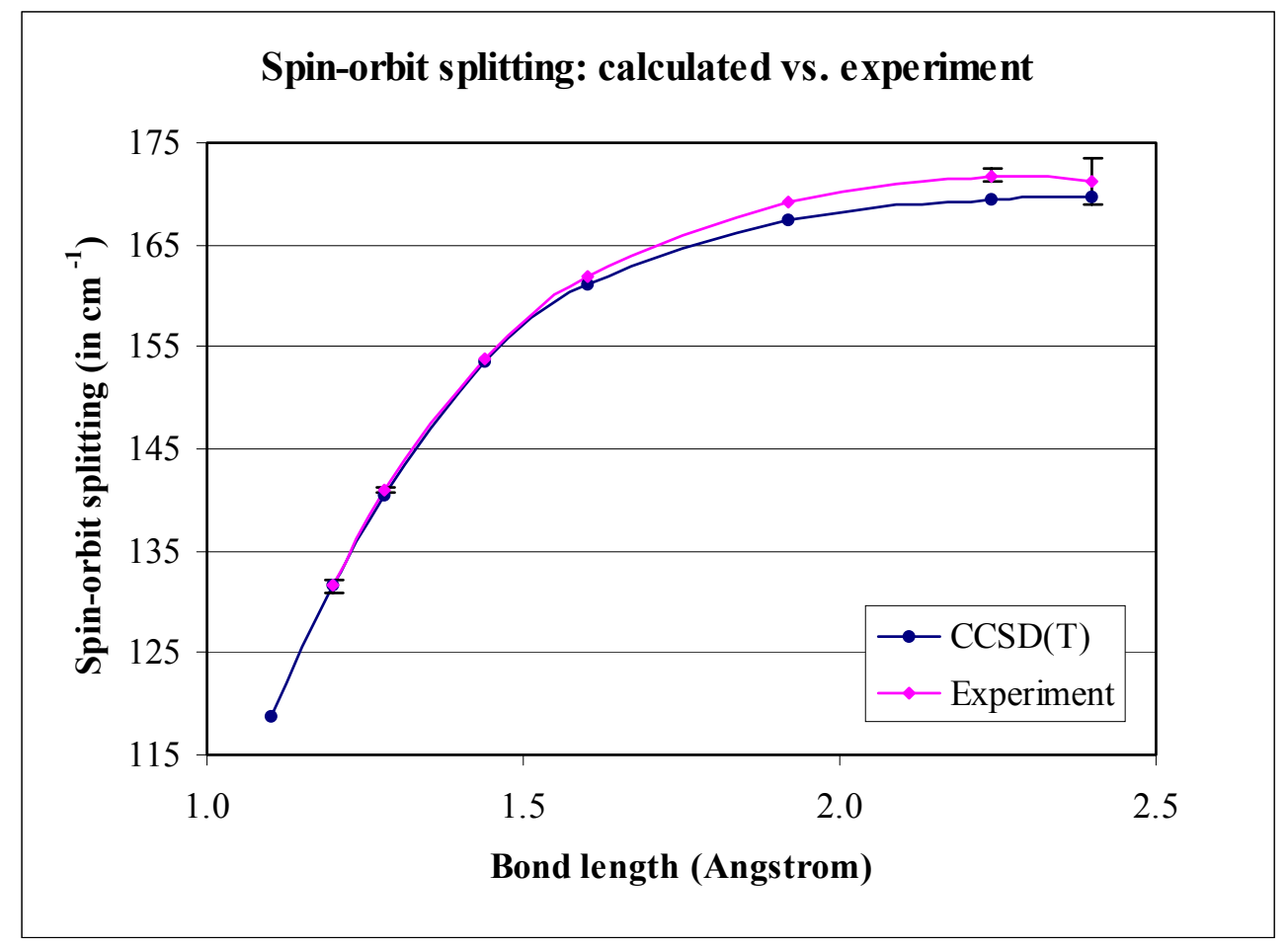

Figure B.2. Calculated and experimental ground state ${ }^{2} \Pi_{1 / 2}{ }^{2} \Pi_{3 / 2}$ spin-orbit splitting.

As can be seen from figure 2 both theory and experiment observe the trend of a lowering of the spin-orbit splitting at shorter bond distances. Additional calculations using the Columbus program package have shown that this trend is almost entirely caused by the one-electron spinorbit integrals. A simple model based upon the bonding character of the orbitals involved and the overlap between orbitals on the Si and F explains this behaviour. Due to the accuracy of the calculated results it has been possible to analyze the fitted experimental results away from the equilibrium bond distance.

\section{$\underline{\text { Relativistic Calculations on the Potential Energy Curves of the } \mathrm{Cl}_{2}} \underline{\text { Molecule }}$}

In the last few years many experiments have been performed on the ground and excited states of the chlorine molecule. However, the results of these experiments are not easily interpreted. At this point in time only the ground state potential energy curve and a part of the excited B state are resolved. Different experiments and interpretations of experimental results have lead to a number of controversies in the literature. A good way to resolve the controversies is the access to accurate theoretical data that can be used to interpret experiments. There is a limited amount of theoretical results available, all of which do not include relativistic effects from the outset. Fully relativistic calculations, using the MOLFDIR program package, have been performed on the chlorine molecule. The ground state and all excited states, dissociating to neutral atoms, and their spectroscopic properties have been calculated. The calculated data is currently analyzed. 


\section{Parallelization of the MOLFDIR Program Package}

The parallelization of the MOLFDIR program package is an ongoing collaborative project. In the first phase (previous project year) the two-electron integral evaluation of SCF process were parallelized. In the second phase the 4-index transformation was parallelized. The first half of the 4-index transformation scales very well with the number of processors. However, the second half of the transformation does not. This is caused by the large amount of communication required to assemble the partial integrals on the various nodes. This is a subject of further development in the next year.

\section{$\underline{\text { Spin-Orbit DFT in NWChem }}$}

Spin-orbit DFT has been implemented in the massively parallel NWChem package. The spinorbit operators used are derived from relativistic effective core potential schemes. With further implementation of spin-orbit integrals based on all-electron spin-orbit operators, the code can also perform all-electron calculations with spin-orbit effect. Current capabilities include single point calculation, geometry optimization and frequency calculations. The exchange functionals used in the implementation are functionals derived for non-spin-orbit calculations, including GGA as well hybrid functionals. Spin-orbit Hartree-Fock calculations can also be carried out. Unrestricted calculations can be performed for open-shell systems. Alternatively, average of configuration calculation can also be carried out.

\section{$\underline{\text { Density Functional Study of the Ground States of aqua anion } \mathrm{UO}_{2}{ }^{2+} \text { Complexes }}$}

One of the principle components of nuclear wastes generated from uranium mining, nuclear power generation and weapons production is in the form of uranyl compounds. Uranium in a (formal) oxidation state of six forms unusually strong short $(\sim 1.7-1.8 \AA$ ) covalent bonds with the two axial oxygens and are usually bonded with four to six equatorial ligands at much longer distances through weak electrostatic interaction. Ligands that selectively bind to the uranyl cation in solutions are generally used to separate and extract the uranyl ions. In addition radioactive nuclear wastes are mainly carried away in the natural system by forming complexes

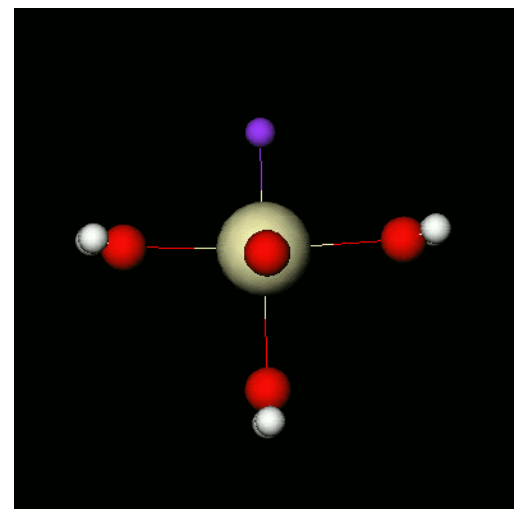

Figure B.3. $\mathrm{UO}_{2} \mathrm{~F}\left(\mathrm{H}_{2} \mathrm{O}\right)_{3}{ }^{+}$ with water and other ligands. Thus the understanding of the chemical and physical properties of the interaction of uranyl with various ligands, especially in the presence of the ubiquitous water solvent, is vitally important. We have chosen to study some simple uranyl-anion $\left(\mathrm{OH}^{-}, \mathrm{F}^{-}\right.$and $\left.\mathrm{Cl}^{-}\right)$systems with coordinated water molecules. An example is shown in figure B.3. Trends in the structures, vibrational frequencies and the binding energies are studied using massivelly parallel density functional methods implemented in NWChem. The number of water molecules in these compounds is determined to be 4, resulting in 5 equatorial ligands. Overall the three aqua anionic uranyl compounds are quite similar in structure and frequencies. It is found that the complexing ability of chloride is very similar to that of the fluoride but somewhat weaker than that of the 
hydroxide. The experimentally observed small differences in the uranyl symmetrical stretch frequencies are reproduced reasonably well with the correct ordering.

\section{$\underline{\text { Density Functional Study of the Excited States of aqua anion UO }} \underline{2}^{2+}$ Complexes}

Uranium forms extremely strong bonds with the two axial oxygen atoms in the linear uranyl ion. The axial uranyl oxygens are substitutionally inert unless the uranyl ion is excited with UV light. Even though the uranyl ion is very stable in its ground state, it is both more oxidizing as an oxidizing agent and more reducing as a reducing agent in its excited state. Notably it can extract hydrogen atoms from organic molecules. Uranyl compounds, when excited with UV light, will relax into the first excited state and it is this first excited state that gives the characteristic fluorescence in the green. Time resolved laser induced fluorescence is the most sensitive tool of uranyl speciation (the determination of uranyl species) in uranyl solutions and uranyl adsorbed surfaces. Crystalline $\mathrm{Cs}_{2} \mathrm{UO}_{2} \mathrm{Cl}_{4}$ has been studied extensively and yielded probably the most detailed spectroscopic data. To assess the performance of density functional with relativistic effective core potentials we studied this compound using the massively parallel NWChem programs. Using the large core Stuttgart RECP, the calculated transition energy is only about half of the experimental value of $20,096 \mathrm{~cm}^{-1}$. With the small core Stuttgart potential the calculated transition energy is within $1,000 \mathrm{~cm}^{-1}$ of the experimental value in local density functional calculation. Several simple aqua uranyl anionic (chloride, hydroxide and fluoride) complexes in the excited states are studied using the small core Stuttgart potential. Full geometry optimization with various numbers of coordinated water molecules in the excited states are carried out and the frequencies and adiabatic transition energies are calculated and compared to the extent possible with experimental values.

\section{Spin-Orbit Density Functional Study of Actinyls}

A number of actinide dioxygen complexes $\left(\mathrm{AcO}_{2}, \mathrm{PaO}_{2}{ }^{+}\right.$and $\mathrm{AnO}_{2}{ }^{2+} \mathrm{An}=\mathrm{U}, \mathrm{Np}, \mathrm{Pu}, \mathrm{Am}$ and $\mathrm{Cm})$ with zero $\left(\mathrm{AcO}_{2}, \mathrm{PaO}_{2}{ }^{+}\right.$and $\left.\mathrm{UO}_{2}{ }^{2+}\right)$ and one to four $\left(\mathrm{NpO}_{2}{ }^{2+}, \mathrm{PuO}_{2}{ }^{2+}, \mathrm{AmO}_{2}{ }^{2+}\right.$ and $\left.\mathrm{CmO}_{2}{ }^{2+}\right)$ f electrons are studied with spin-orbit DFT. All optimized geometries are linear with decreasing actinide-oxygen bond lengths. The three closed shell systems have the longest bond lengths and show the largest variation (with a range of $0.18 \AA$ ). The f electrons occupy the nonbonding orbitals and the bond lengths of the later actinyls do not show appreciable change for $\mathrm{NpO}_{2}{ }^{2+}$, $\mathrm{PuO}_{2}{ }^{2+}, \mathrm{AmO}_{2}{ }^{2+}$ and $\mathrm{CmO}_{2}{ }^{2+}$. Calculations show that spin-obit effect elongates the bond length of $\mathrm{PuO}_{2}{ }^{2+}$ by $0.016 \AA$. Further calculations will be carried out to determine the ground state assignment and frequencies.

\section{Ab Initio Study of the Low-Lying Electronic States of UO}

The UO molecule has four nonbonding electrons occupying the lowest nonbonding orbitals formed from $\mathrm{U} 5 \mathrm{f}$ and $7 \mathrm{~s}$ orbitals. There are a rich number of electronic states resulting from these configurations and only a few can be explored experimentally. Experimental results show that the ground state is an $\Omega=4$ state and the next higher state is also of $\Omega=4$ symmetry, lying

only $296 \mathrm{~cm}-1$ above the ground state. The ground state results from the $\mathrm{f}^{3} \mathrm{~s}^{1}$ configuration around 
$1.8 \AA$ and the next higher state from $\mathrm{f}^{2} \mathrm{~s}^{2}$ configuration at a longer bond length. Spin-orbit CI calculations confirm the experimentally assigned configurations. More low-lying states are being calculated.

\section{The Ohio State University (Bursten, Li)}

Relativistic DFT Studies of Organoactinide Complexes have been performed and our accomplishments and results are presented in the sections below.

\section{Calculations of the Vibrational Frequencies and Intensities of Laser-Abated Products of $\underline{\mathrm{Th}+\mathrm{CO}}$}

Using gradient-corrected DFT methods, we have determined the geometric structures and discussed the electronic structures and bonding of a series of laser-ablated $\mathrm{Th}+\mathrm{CO}$ reaction products, including $\mathrm{CThO}, \mathrm{CThO}^{-}, \mathrm{OTh}\left(\eta^{3}-\mathrm{CCO}\right),\left(\eta^{2}-\mathrm{C}_{2}\right) \mathrm{ThO}_{2}, \mathrm{OThCCO} \mathrm{Th}(\mathrm{CO})_{\mathrm{x}}$ and $\operatorname{Th}(\mathrm{CO})_{\mathrm{x}}{ }^{-}(\mathrm{x}=1-2)$ species. While the Th chemistry might seem to be analogous to that of the $\mathrm{U}$ chemistry, we have found remarkable difference in these two similar series of complexes. For example, akin to the $\mathrm{ThO}_{2} \mathrm{vs} \mathrm{UO}_{2}{ }^{2+}$, the OThCCO is bent while OUCCO is linear. In addition, the ground state CUO is a singlet linear molecule, whereas the CThO is found to be a triplet bent molecule that has the carbene (i.e. carbide-oxide) structure $(: \mathrm{C}=\mathrm{Th}=$ : $)$. This triplet $\mathrm{CThO}$ molecule is the first actinide-containing carbene compound, the importance of which has been recently reported in the January 10, 2000 issue of Chemical \& Engineering News, P. 26.

\section{Calculations of the Vibrational Frequencies and Intensities of Laser-Abated Products of} $\underline{\mathrm{Th} / \mathrm{U}+\mathrm{CO}_{2}}$

Using similar DFT methods, we have determined the geometric structures and discussed the electronic structures and bonding of a series of laser-ablated $\mathrm{U} / \mathrm{Th}+\mathrm{CO}_{2}$ reaction products, including $\mathrm{OAnCO}, \mathrm{OAnCO}^{+}, \mathrm{O}_{2} \mathrm{An}(\mathrm{CO})_{2}$, and $\mathrm{O}_{2} \mathrm{An}(\mathrm{CO})_{2}^{-}(\mathrm{An}=\mathrm{Th}, \mathrm{U})$. The calculations of the vibrational frequencies and infrared intensities are in excellent agreement with the experimental measures for Ne matrix. Our calculations have not only confirmed the experimental assignment of the infrared spectra of these species, but also helped in a few occasions the experimentalists to identify some weak absorptions in the experimental spectra and to correct some ambiguous assignments of the spectra. These calculations indicate that the PW91 generalized gradient DFT methods can predict the vibrational frequencies in good accuracy and spin-orbit coupling plays little role in determining the ground-state geometries and vibrational properties of actinide complexes.

\section{Matrix Effects to the Ground State Reversal of CUO}

Our previous theoretical calculations found a linear singlet $\left({ }^{1} \Sigma^{+}\right)$ground state for the triatomic uranium carbide-oxide, CUO. The calculated vibrational frequencies and intensities are in excellent agreement with experimental values for Ne matrix. A recent experimental work reveals that the CUO molecule exhibits significantly blue-shifted frequencies in an Ar matrix, indicating a different ground state. We have found from DFT and ab initio calculations that the first excited state $\left({ }^{3} \Phi\right)$ of CUO in gas-phase lies only about $1 \mathrm{kcal} / \mathrm{mol}$ higher in energy than the 
singlet ground state. We have designed a matrix model to elucidate the interaction between the matrix cluster and the CUO molecule. Our density functional geometry optimizations (see Figure B.4) of CUO.(NG) supermolecules $(\mathrm{NG}=\mathrm{Ne}, \mathrm{Ar} ; \mathrm{x}=14,17,20,23)$ have revealed nonnegligible matrix-CUO interaction; the triplet state has been considerably stabilized due to the interactions with the Ar matrix. Our calculations not only have helped to explain the unique ground state reversal of CUO molecule via matrix interaction, but also have underscored the significant theoretical advance in being able to quantum-mechanically simulate the weak matrix interaction.

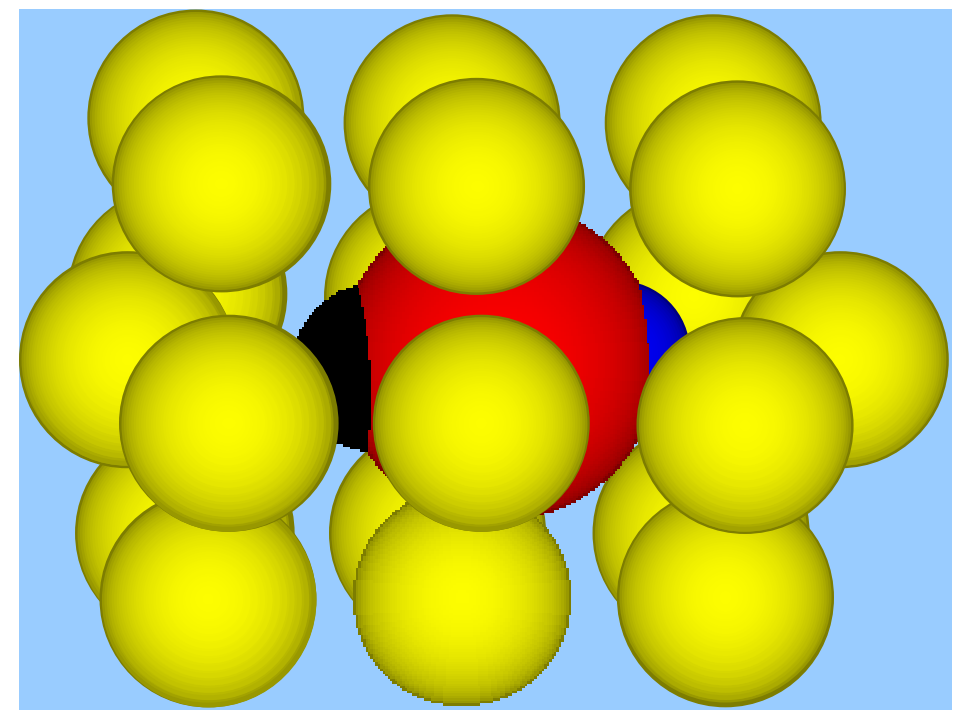

Figure B.4. ${ }^{3} \Phi-$ State CUO Molecule in an $\operatorname{Ar}_{20}\left(\mathrm{C}_{6 \mathrm{v}}\right)$ Matrix Cluster

\section{$\underline{\text { Geometries and Electronic Structures of } \mathrm{An}(\mathrm{OR})_{4}(\mathrm{An}=\mathrm{Th}-\mathrm{Am} ; \mathrm{R}=\mathrm{H}, \mathrm{Me}, \mathrm{Ph})}$}

Using the PW91 methods, we have fully optimized the geometries of the $\mathrm{An}(\mathrm{OR})_{4}(\mathrm{An}=\mathrm{Th}-$ $\mathrm{Am}, \mathrm{R}=\mathrm{H}, \mathrm{Me}, \mathrm{Ph}$ ) series of compounds (see figure B.4a). The substituent effects on the An-O bond lengths, the electronic structures and the binding energies of these complexes have been discussed. We have also examined the spin-orbit coupling effects and the ligand-field effects on these actinide complexes. We are currently investigating the optical properties of these compounds using the state-of-the-art excited-state DFT methods and ab initio approach. 


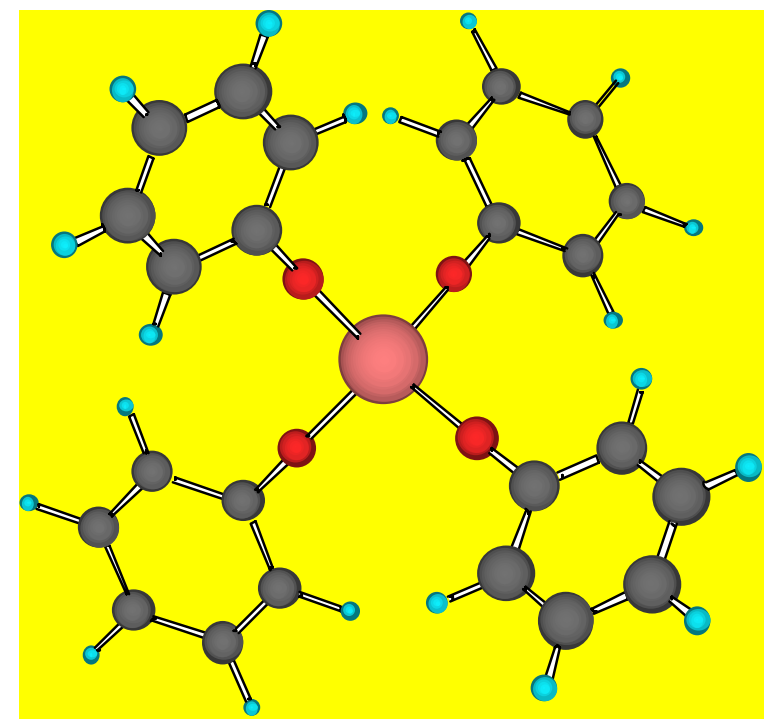

Figure B.4a. Optimized Geometry Structures of $\mathrm{Pu}(\mathrm{OPh})_{4}$ Molecule $\left(\mathrm{Ph}=\mathrm{C}_{6} \mathrm{H}_{5}\right)$

$\underline{\text { Eloret }}$

\section{Development of Relativistic Basis Sets and Relativistic Approximations}

Two separate uses were made of the MPP time. The first was the development of basis sets for the actinide atoms. Double and triple zeta quality SCF basis sets have been optimized for Pa - Lr, and correlating functions have been generated for some of these. For the remainder, further code development is needed. The second use was the testing and benchmarking of the approximate relativistic methods in NWChem. This use is in the early stages of determining the best way of performing the evaluation.

\section{$\underline{\text { Stevens Institute of Technology }}$}

Molecular Structure, Spin-Orbit Coupling and Other Relativistic Effects with Applications to Electronic States of $\mathrm{RuO}, \mathrm{EuO}_{2}{ }^{2+}$ and $\mathrm{AmO}_{2}{ }^{2+}$.

The COLUMBUS program was used for Spin-Orbit Configuration Interaction (SOCI) calculations for many electronic states of RuO. We have performed SOCI calculations using a large-core (LC) averaged relativistic effective core potential (ARECP) and the corresponding spin-orbit operator. In addition, NWChem, GAMESS, GAUSSIAN 98, and COLUMBUS were used for SCF calculations with SC (small core)-ARECPs and LC-ARECPs and for all-election calculations. Comparing the results which were calculated using the COLUMBUS program with the results which were calculated using NWchem, GAMESS and GAUSSIAN 98, we found that SC-ARECP results generally show better agreement with all-electron results than LC-ARECP results. The results calculated using NWChem are in good agreement with the GAMESS results, but GAUSSIAN 98 results do not agree well with those due to both NWChem and GAMESS. 


\section{The Ohio State University (Pitzer)}

\section{$\underline{\text { Structure and Spectra of } \mathrm{UO}_{2} \underline{F}_{2}}$}

Uranyl fluoride $\left(\mathrm{UO}_{2} \mathrm{~F}_{2}\right)$ is a product of the reaction of $\mathrm{UF}_{6}$ with moisture. There are ca. 200,000 tons of (depleted) $\mathrm{UF}_{6}$ stored in Ohio and ca. 500,000 tons stored in Kentucky. Thus the detection of a luminescent product of leaking $\mathrm{UF}_{6}$ with (humid) air may be useful.

Studies of solutions containing $\mathrm{UO}_{2} \mathrm{~F}_{\mathrm{n}}{ }^{2-\mathrm{n}}$ species have shown that $\mathrm{UO}_{2} \mathrm{~F}_{2}$ luminescence is the most intense. Thus we have begun the study of the structure and spectra of $\mathrm{UO}_{2} \mathrm{~F}_{2}$. Initially we were studying the isolated molecule, and then we added solvating water molecules, and optimized the structure to get the spectra for species in solution. The optimization work was done by DFT method on MPP1, and we put 2 waters to $\mathrm{UO}_{2} \mathrm{~F}_{2}$ first, with trans and cis geometry respectively.

The optimizing results show that for these two geometries they are pretty close in energy and they both have imaginary vibrational modes, which correspond to water moving parallel to UOF plane. So we added the $3^{\text {rd }}$ water, also with two geometries. The trans optimized structure is higher in energy than cis by about $5000 \mathrm{~cm}^{-1}$, and there are imaginary frequencies for both geometries too. For all these geometries ( 2 waters and 3 waters), they are $\mathrm{C}_{2 \mathrm{v}}$ symmetry. After we added the $4^{\text {th }}$ water, the optimization gave no imaginary modes, which made us conclude that this is the minimum. The 6-coordinate structure clearly shows that there is strong hydrogen bonding with the F's and this is what stabilizes the 6-coordinate structure. The binding energies of the $3^{\text {rd }}$ and $4^{\text {th }}$ waters are 18 and $26 \mathrm{kcal} / \mathrm{mol}$ respectively. And this final structure is $\mathrm{D}_{2}$ symmetry. The structure is shown in the figure B.5.

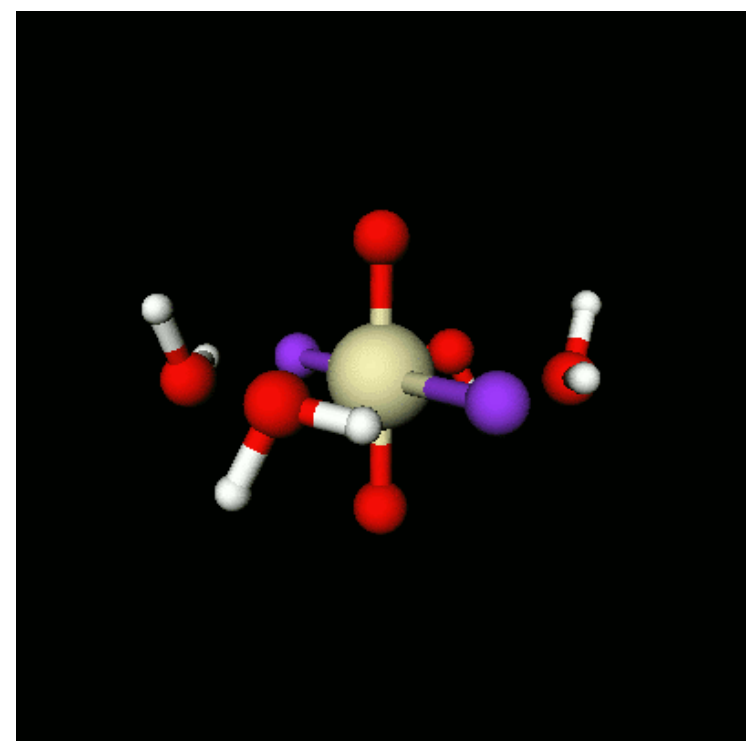

Figure B.5. $\mathrm{D}_{2}$ structure for $\mathrm{UO}_{2} \mathrm{~F}_{2}\left(\mathrm{H}_{2} \mathrm{O}\right)_{4}$
The $a b$ initio calculations were performed using the Columbus program. We used relastivistic core potentials to replace the core electrons on all atoms, and basis sets of polarized double-zeta size that was developed in our group. Initial structural studies used DFT (courtesy of D.A. Dixon) to give a (non-planar) $\mathrm{C}_{2 \mathrm{v}}$ structure.

MOs are obtained from SCF and MCSCF calculations. The spin-orbit interaction and electron correlation are included using spin-orbit configuration interaction (SO-GUGA in the Columbus programs). Spin-orbit and equatorialligand $\left(\mathrm{F}^{-}, \mathrm{H}_{2} \mathrm{O}\right)$ interactions compete in determining the splittings of the known ${ }^{3} \Delta_{\mathrm{g}}$ luminescent state of the uranyl ion. 


\section{Syracuse University}

The computational studies part of the work was done in a collaborative effort between Syracuse University and PNNL.

"Fast" Methods of Correlated Calculations: A Study of the RI-MP2 Approach Applied to Tetramethoxycalix[4]arene

The RI-MP2 method combines the "resolution of the identity" integral approximation (RI) with second-order many-body perturbation theory (MP2) to produce a "fast" version of the traditional MP2 approach which is particularly useful for large-scale calculations. While most "fast" methods focus on ways to take advantage of the sparsity of interactions common in spatially extended molecules with modest basis sets, the RI approximation targets the other end of the spectrum: modestly sized molecules with large per-atom basis sets, as are typically used for high-accuracy calculations of thermodynamic results or in popular basis set extrapoliation techniques. Not only does the RI approximation take advantage of the near-redundancy of large basis sets, it also shifts the dominant $\mathrm{N}^{5}$ work of the MP2 from the four-index transformation in the tradistional implementation to a very large matrix multiplication operation which is more readily and efficiently parallelized than the transformation. In this way, the RI-MP2 approach is able to "take advantage of" both the size of large molecules and the features of modern MPPs and parallel algorithms to provide much better performance than the "exact" MP2 in large-scale calculations in a region of the problem space that other "fast" methods have trouble addressing. It is worth noting that although the RI approximation has to date seen the most extensive uses at the MP2 level, implementations have been demonstrated a many levels of theory ranging from Hartree-Fock and DFT to coupled cluster theory.

In this work, we have used the RI-MP2 approach to study the relative energies of conformations of tetramethoxycalix[4]arene and examined the performance of the RI-MP2 method itself using these large molecules as a test case. Tetramethoxycalix[4]arene is a cage-like structure which can be envisioned as being constructed of four anisole molecules linked by methylene bridges. There are four different conformations available to the molecule, depending on the relative orientations of the four anisole methoxy groups: all pointing the same directions ("cone"), one directed opposite the other three ("partial cone"), and in pairs - either adjacent ("1,2 alternate") or opposite ("1,3 alternate") facing the same way. Solution-phase experimental measurements of conformer stability place them within a $10 \mathrm{kcal} \mathrm{mol}^{-1}$ range of relative energies. Unfortunately, neither the absolute energies nor even the trends in stability reported experimentally are reproduced by commonly used forcefields or semiempirical methods; differences are often attributed to solvation effects. Calixarenes are playing an increasingly important role in hostguest chemistry, and in order to study them effectively, it is necessary to have a more solid theoretical understanding of how to model them reliably. Therefore a set of DFT, exact MP2, and RI-MP2 calculations were carried out to provide "benchmark" results for the development of more accurate parameterizations of lower-level methods.

Structures were optimized at the B3LYP/DZVP2 level and single-point energy evaluations carried out using the exact MP2 with cc-pVDZ and cc-pVTZ basis sets, and the RI-MP2 method with those as well as the aug-cc-pVTZ set (cc-pVTZ on H). The largest calculations comprised 
$2460 \mathrm{AO}$ basis functions and 8260 fitting functions. Calculations show both the DFT and (RI-)MP2 results reproducing the experimental ordering of conformers, and the (RI-)MP2 calculations in reasonable agreement with the relative energies.

These calculations, among the largest reported to date at the MP2 level, were also used to investigate the performance and scalability of the RI-MP2 method on the MSCF's IBM $\mathrm{RS} / 6000 \mathrm{SP}$. These studies show excellent scaling from 16 to 128 processors. Calculations on the same molecule with basis sets of increasing size (i.e. basis set extrapolation studies) show the exact MP2 scaling at roughly $\mathrm{N}^{\wedge} 3.4$ and the RI-MP2 calculations at $\mathrm{N}^{\wedge} 2.5$ (the theoretical scalings for this situation are $\mathrm{N}^{\wedge} 4$ and $\mathrm{N}^{\wedge} 3$ ), indicating the performance advantage of the RI-MP2 approach. Rough estimates suggest that if they were performance, exact MP2 calculations at the aug-cc-pVTZ level would require approximately 90 times longer than the RI-MP2 calculations did.

\section{$\underline{\text { University of Toulouse (France) }}$}

The Structure of $\mathrm{AnX}_{2}{ }_{2+}$ ions ( $\mathrm{An}=\mathrm{U}, \mathrm{Pu}$ and $\left.\mathrm{X}=\mathrm{S}, \mathrm{Se}, \mathrm{Te}\right)$ Valence-Isoelectronic with $\mathrm{AnO}_{2}{ }^{2+}$ and the Nature of Actinyl-Phosphate Binding.

In nature the uranyl ion $\left(\mathrm{UO}_{2}{ }^{2+}\right)$ is found to be linear whereas the plutonyl ion $\left(\mathrm{PuO}_{2}{ }^{2+}\right)$ is found to form a bend structure. From theoretical and experimental point of view it is interesting to understand the trends going down along column 16 in the periodic table, i.e. from $\mathrm{O}$ to the heavier Te. The calculations have been performed using the NWCHEM code, developed at EMSL, and the Gaussian package. The surprising outcome from the calculations is that only the uranyl, the uranium atom with two oxygens forms a closed shell linear molecule. Molecules

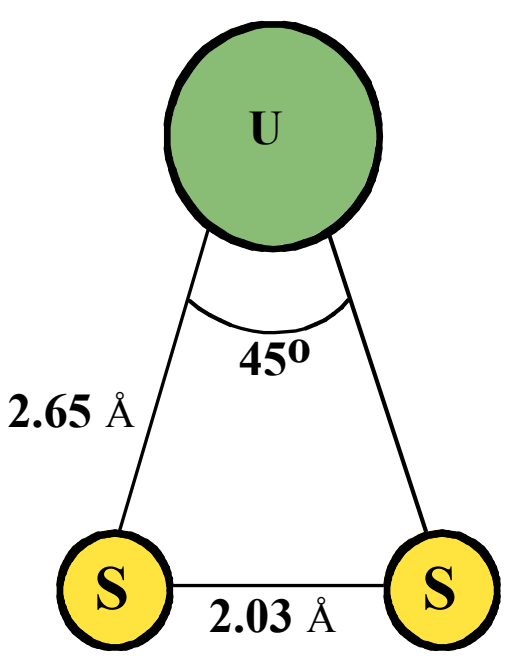

Figure B.6. Calculated geometry of the $\mathrm{US}_{2}^{2+}$ formed using $\mathrm{S}, \mathrm{Se}$ or Te have quintet ground states and are bend structures with X-U-X angles around 50 degrees and a substantial $\mathrm{X}-\mathrm{X}$ bonding. The structure of $\mathrm{US}_{2}{ }^{2+}$ is shown as an example in figure B.6. In summary, the formation of a closed shell uranyl ion seems to be a unique case.

All over the world, at DOE sites but also in France, extraction techniques are used to recover uranium and plutonium and to separate these elements from each other. It is known that ligands containing phosphorus and sulfur work well in the extraction process, although the mechanisms are not fully understood. In order to increase the understanding of actinyl-ligand bonding the phosphate ligands $\mathrm{PO}_{2} \mathrm{H}_{3}, \mathrm{PO}_{2} \mathrm{H}_{2}{ }^{-}$and $\mathrm{PS}_{2} \mathrm{H}_{3}$ and $\mathrm{PS}_{2} \mathrm{H}_{2}{ }^{-}$are studied. These systems are studied with the NWCHEM code. Calculations on these compounds were started this year and the analysis is still continuing. 


\section{Appendix_C - Full Report for Third Year Activities and Accomplishments}

The activities and the accomplishments are described in detail and are grouped by research institution.

Pacific Northwest National Laboratory

Relativistic Calculations on the Electric Field Gradients and NMR Chemical Shifts of ${ }^{139}$ La Complexes

As part of a Level VI LDRD project we have performed ab initio calculations on ${ }^{139} \mathrm{La}^{3+}$ in the $\left[\mathrm{La}(\mathrm{NO} 3)_{3}\left(\mathrm{H}_{2} \mathrm{O}\right)_{5}\right] \cdot \mathrm{H}_{2} \mathrm{O}$ crystal structure (Figure C.1). These calculations were done on the large IBM SP2 in the Molecular Sciences Computing Facility using the parallel program packages NWChem and ADF 2000.02. NWChem was used to get the optimal positions for the hydrogen atoms in the experimental structure, as these atoms cannot be elucidated with X-ray experiments. In these geometry optimizations we used a small-core Stuttgart ECP and basis set for La, and TZVP basis sets for all other elements. Only the hydrogen atoms were allowed to move during the optimization, the other atoms were kept frozen in their experimental positions. ADF was used to calculate the nuclear magnetic resonance (NMR) electric field gradient (EFG) and chemical shift tensor for ${ }^{139} \mathrm{La}^{3+}$. In these calculations we used the approximate relativistic ZORA Hamiltonian with spin-orbit coupling and the VWN and PW91 potentials for exchange and correlation functional, and we used the high quality ZORA V basis sets.

In our initial NMR property calculations we used a modeled MM3 structure obtained by Ben Hay (PNNL). This structure is found to be close to the known experimental data. The calculated NMR parameters were forwarded to Herman Cho who then simulated the NMR spectrum with this data. The simulated MM3-based and experimental NMR spectra show reasonable agreement; the simulated spectrum is slightly broader and has two central peaks, which is caused by the considerable asymmetry in the EFG. The line width is dominated by the EFG. The chemical shift anisotropy has only a small effect on the total line width. As the line width depends on square of the EFG value, the simulated spectrum will be very sensitive to the calculated EFG parameters. Our good agreement shows that our

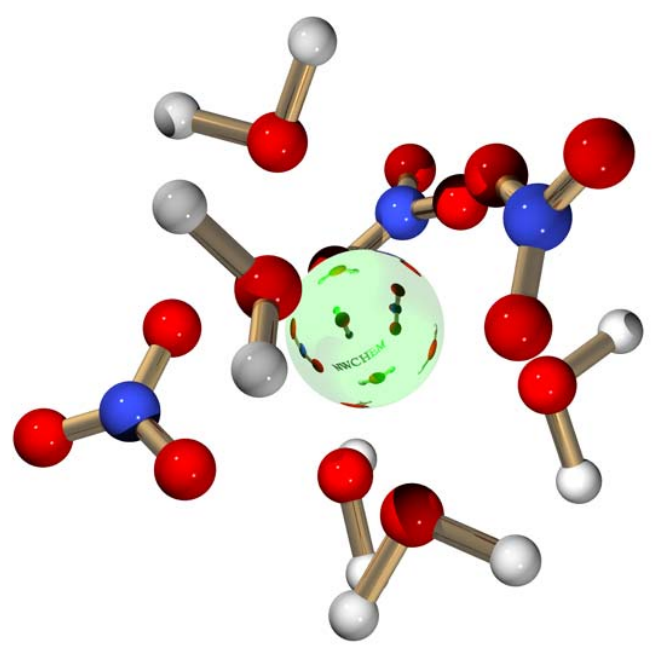

Figure C.1. Experimental $\mathrm{La}\left(\mathrm{NO}_{3}\right)_{3}\left(\mathrm{H}_{2} \mathrm{O}\right)_{5}$ structure with calculated hydrogen positions calculations can produce NMR parameters close to experiment. NMR parameters are very sensitive to geometrical changes. We therefore performed similar calculations using the experimental structure, and the hydrogen positions, lacking in the experimental structure data, were calculated via an NWChem geometry optimization. In contrast to the results from the MM3 structure, the calculated asymmetry parameter is very close to 1.00 . As a result the simulated spectra is now found to be to narrow. Based on some additional simulations where the 
asymmetry parameter $\eta$ was varied, we believe that the experimental value will be between 0.90 and 0.95. An additional parameter that should be considered is that NMR experiments are done at room temperature while the calculations assume a temperature of zero.

\section{$\underline{\text { Relativistic Calculations on the Electric Field Gradients of }{ }^{99} \mathrm{Tc} \text { and }{ }^{187} \mathrm{Re} \text { in Pertechnetate }}$ and Perrhenate Compounds.}

Calculations have been performed to obtain an estimate of the ${ }^{99} \mathrm{Tc}$ EFG in an ammonium pertechnetate crystal structure. The ammonium perrhenate, which has structural parameters very close to the pertechnetate, has been studied extensively and nuclear quadrupole resonance data is available. Both the pertechentate and the perrhenate consist of a slightly distorted tetrahedral $\left[\mathrm{XO}_{4}\right]^{-}$unit $(\mathrm{X}=\mathrm{Tc}$ or $\mathrm{Re})$, surrounded by tetrahedral and flattened tetrahedral ammonium ions. For both structures the structures have not been resolved to enough detail to elucidate the slight distortion of the tetrahedral $\left[\mathrm{TcO}_{4}\right]^{-}$or $\left[\mathrm{ReO}_{4}\right]^{-}$unit. For perrhenate it is known that the $\mathrm{Re}-\mathrm{O}$ bond lengths are equal but that not all the oxygen angles are the same. In our calculations we first focused on a free tetrahedral $\left[\mathrm{ReO}_{4}\right]^{-}$unit and distorted this structure by slightly displacing some of the oxygen atoms from their tetrahedral positions. We found that we can reproduce the nuclear quadrupole coupling constant (NQCC) for ${ }^{187} \mathrm{Re}(110 \mathrm{MHz})$ by displacing one atom around 0.03 Angstrom from its tetrahedral position. We used the same displacement in our calculations on the $\left[\mathrm{TcO}_{4}\right]^{-}$unit. The calculations show that the EFG in ${ }^{99} \mathrm{Tc}$ is a factor of 2.4 smaller than in ${ }^{187} \mathrm{Re}$. In addition, the nuclear quadrupole moment of ${ }^{99} \mathrm{Tc}(-0.129 \mathrm{Barn})$ is a factor of 16 smaller than in ${ }^{187} \mathrm{Re}(2.070$ Barn $)$. Based on this data we expect the ${ }^{99} \mathrm{Tc}$ NQCC to be around $2.8-2.9 \mathrm{MHz}$, a factor of 38 smaller compared to ${ }^{187} \mathrm{Re}$. We are currently analyzing the calculated data, looking at covalency and bonding properties, to understand why the EFG in

${ }^{99} \mathrm{Tc}$ differs so much from ${ }^{187} \mathrm{Re}$. We plan to simulate the full ammonium pertechnetate structure to understand the influence of the surrounding ammonium atoms on the EFG value, and to understand an anomalous temperature dependence that has been observed in both pertechnetate and perrhenate.

\section{$\underline{\text { Relativistic Calculations on the Core-Hole Spectra in Transition Metal Compounds }}$}

We have started collaboration with Jim Rustad (PNNL) calculating the $2 p$ core-hole spectra of transition metals. Experiments have and are performed on the core-hole spectra of transition metal compounds but the interpretation of the results, predominantly the oxidation state of the metal, has been hampered by the absence of good theoretical spectra of these $2 p$ core-holes. When studying core-hole spectra the relativistic effects become very dominant and the only valid way of computing these spectra is to perform fully relativistic calculations. These calculations are performed using the MOLFDIR program package. We are currently working on the $2 p$ corehole spectra of $\mathrm{Cr}$ in various oxidation states.

\section{Relativistic Calculations on the Electric Field Gradients and NMR Chemical Shifts of Uranyl Carbonate Complexes}

A possible approach for the speciation of actinide complexes in soils, groundwater and in waste tanks at DOE sites is the use of Nuclear Magnetic Resonance (NMR) techniques. The signal from a NMR measurement is element and bond specific and, hence, is therefore an excellent tool 
for speciation. No NMR experiments have been performed on the actinide elements in complexes. Some experiments have measured the NMR signals of the lighter elements (like oxygen and carbon) surrounding the actinides. In order to do experiments on actinide elements so-called "hot" isotopes have to be used. To get some insight in the possible outcome of NMR experiments on actinide elements and their surrounding (lighter) elements, ab initio relativistic theoretical calculations have been performed. The NMR properties of the elements ${ }^{235} \mathrm{U},{ }^{17} \mathrm{O}$ and ${ }^{13} \mathrm{C}$ in the molecule series $\mathrm{UO}_{2}{ }^{2+}, \mathrm{UO}_{2} \mathrm{CO}_{3}, \mathrm{UO}_{2}\left(\mathrm{CO}_{3}\right)^{2-}$ and $\mathrm{UO}_{2}\left(\mathrm{CO}_{3}\right)_{3}{ }^{4-}$ (Figure 3) were calculated using the MOLFDIR and ADF computational packages on the NWMPP1 at EMSL. These calculated properties were then used to produce simulated NMR spectra based on the available experimental settings at EMSL. The calculated electric field gradient (EFG) on ${ }^{235} \mathrm{U}$ was found to be very large. ${ }^{235} \mathrm{U}$ also has a large nuclear quadrupole moment (4.936 Barn). When we apply this data to standard formulations for spin-lattice relaxation NMR experiments we find that the $T_{1}$ relaxation time would be in the nanosecond range, too short to be handled by current NMR technology. For solid-state measurements the lines would be split by $5-6 \mathrm{GHz}$, which would make this experiment extremely difficult or even impossible to do. The calculated results suggested, however, that Nuclear Quadrupole Resonance (NQR) could be used to probe the actinide element in the complexes.
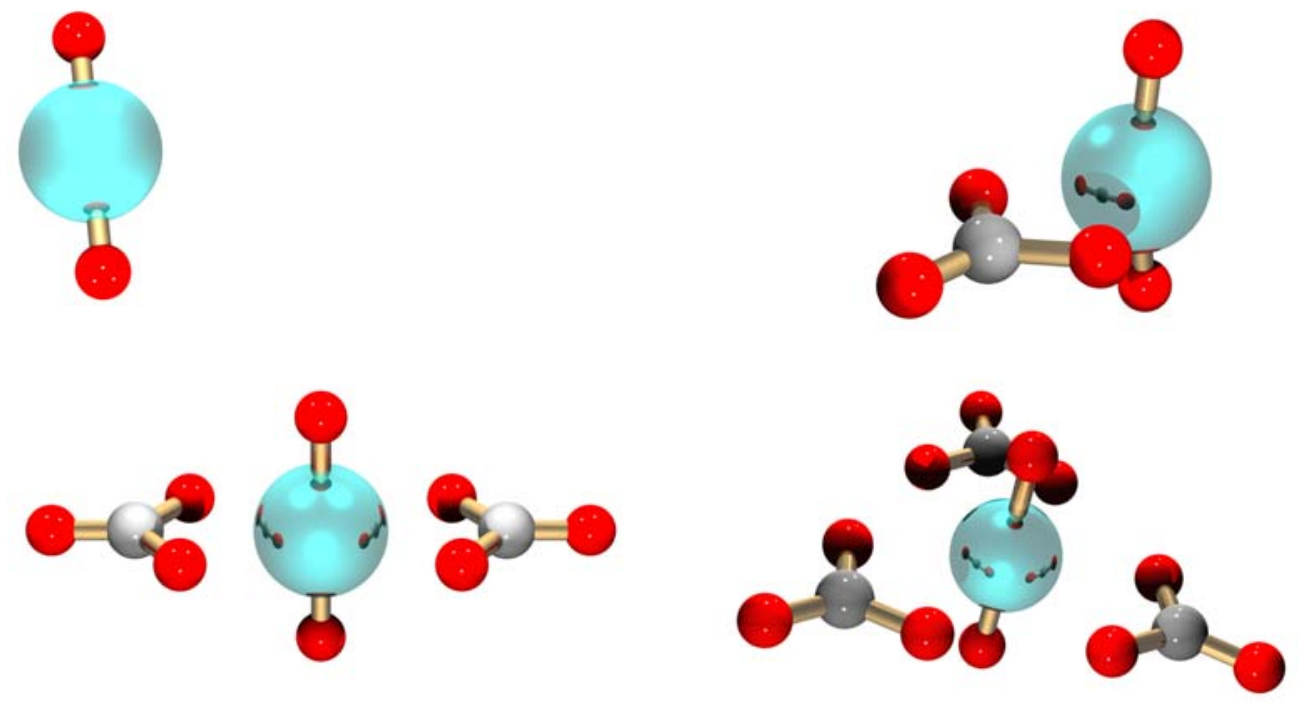

Figure C.3. Uranyl geometrical structures used in the NMR calculations. Top row: $\mathrm{UO}_{2}{ }^{2+}$ (left) and $\mathrm{UO}_{2} \mathrm{CO}_{3}$ (right); Bottom row: $\mathrm{UO}_{2}\left(\mathrm{CO}_{3}\right)_{2}{ }^{2-}$ (left) and $\mathrm{UO}_{2}\left(\mathrm{CO}_{3}\right)_{3}{ }^{4-}$ (right). 


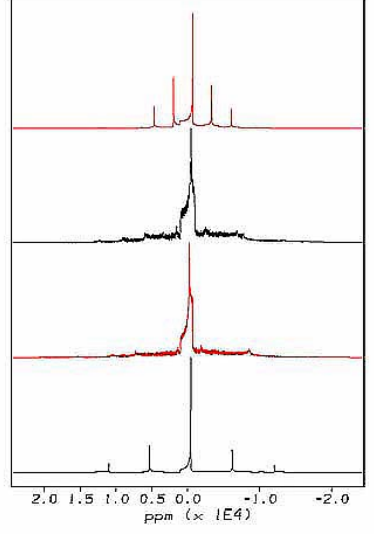

a.

b.

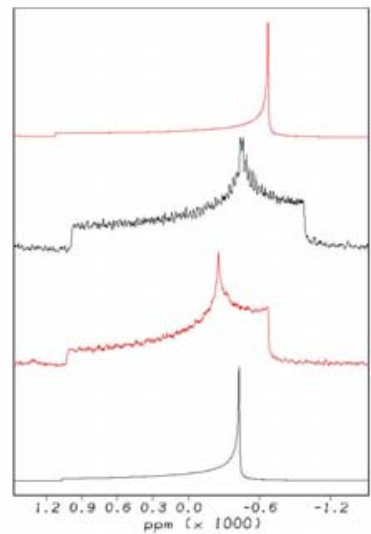

C.

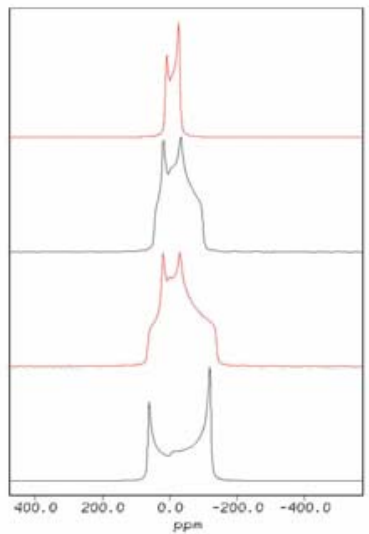

Figure C.4. Simulated NMR spectra for the ${ }^{17} \mathrm{O}$ of the uranyl unit in, from top to bottom in each of the three pictures, $\mathrm{UO}_{2}{ }^{2+}, \mathrm{UO}_{2} \mathrm{CO}_{3}, \mathrm{UO}_{2}\left(\mathrm{CO}_{3}\right)_{2}{ }^{2-}$ and $\mathrm{UO}_{2}\left(\mathrm{CO}_{3}\right)_{3}{ }^{4-}$ based on calculated EFG, shieldings (CS) and their anisotropy; a. All transitions, both EFG and CS included in simulation; b. Central $1 / 2 \rightarrow 1 / 2$ transition, both EFG and CS included in simulation; c. Central $1 / 2 \rightarrow 1 / 2$ transition, CS omitted in simulation. Note: the spectra were calculated assuming a field of 7.04 Tesla. The relative intensities between the complexes are not on scale, the $\mathrm{UO}_{2} \mathrm{CO}_{3}, \mathrm{UO}_{2}\left(\mathrm{CO}_{3}\right)_{2}{ }^{2-}$ have lower intensities relative to $\mathrm{UO}_{2}{ }^{2+}$ and $\mathrm{UO}_{2}\left(\mathrm{CO}_{3}\right)_{3}{ }^{4-}$.

An alternative probe of the bonding properties of uranyl containing molecules would be the measurement of ${ }^{17} \mathrm{O}$ and ${ }^{13} \mathrm{C}$ EFGs and chemical shifts. We have calculated the EFG and shielding parameters for oxygen and carbon. Figure 4 a shows the simulated NMR spectra of the ${ }^{17} \mathrm{O}$ directly bonding to the uranium atom for various uranyl carbonates. A very interesting observation is that there is a large influence of the chemical shift anisotropy on the final shape of the simulated spectrum (comparing figures $4 \mathrm{~b}$ and $4 \mathrm{c}$ ), this in contrast to the relatively small effect in the lanthanum calculations discussed above. No experimental EFG data is available for ${ }^{17} \mathrm{O}$ in uranyl. However, there is experimental chemical shift data available for the ${ }^{17} \mathrm{O}$ and ${ }^{13} \mathrm{C}$ atoms in uranyl molecules in solution. Good agreement is obtained between calculated and experimental results, especially for the ${ }^{17} \mathrm{O}$ in the uranyl unit. The relative errors for ${ }^{17} \mathrm{O}$ in the carbonate units is larger and is most likely caused by the fact that our calculations were done in gas phase while experiments were done in solution. Preliminary results, using the COSMO model, show the calculated chemical shifts improving when the solvation effects are included in the calculations. We are planning to perform mixed quantum mechanical - molecular mechanical $(\mathrm{QM} / \mathrm{MM})$ calculations to understand the effects of solvation $\left(\right.$ in $\left.\mathrm{H}_{2} \mathrm{O}\right)$ on the structure and the NMR properties. Currently uranyl-containing crystals are made as part of an LDRD project. Based on the crystal structure of these compounds we will perform embedded cluster calculations, simulating the environment with point charges. The calculated data will be used to simulate the ${ }^{17} \mathrm{O}$ spectra that will be measured simultaneously. 
$\underline{\text { Spin-Orbit CI and Density Functional Study of the Excited States of Hydrated UO }} \underline{\mathbf{A}}^{+}$ $\underline{\left(\mathrm{A}=\mathrm{OH}^{-}, \mathrm{F}^{-} \text {and } \mathrm{Cl}^{-}\right)}$

Effective core potentials with 60,68 and 78 core electrons replaced are used for calculations on the ground and excited state properties of $\mathrm{UO}_{2} \mathrm{Cl}_{4}{ }^{2-}$ to test the validity of the core potentials. For ground state properties all potentials give results close to each other and to the experimental results. But the excitation energies calculated with the large core potential (78 electrons in the core) are too low. The excited state structures for simple aqua uranyl-anion complexes, $\mathrm{UO}_{2} \mathrm{OH}\left(\mathrm{H}_{2} \mathrm{O}\right)_{4}{ }^{+}, \mathrm{UO}_{2} \mathrm{~F}\left(\mathrm{H}_{2} \mathrm{O}\right)_{4}{ }^{+}$and $\mathrm{UO}_{2} \mathrm{Cl}\left(\mathrm{H}_{2} \mathrm{O}\right)_{4}{ }^{+}$are optimized with LDA and B3LYP theory using Stuttgart small core relativistic effective core potentials. The calculated excitation energies are in the order of $\mathrm{UO}_{2} \mathrm{OH}\left(\mathrm{H}_{2} \mathrm{O}\right)_{4}{ }^{+}>\mathrm{UO}_{2} \mathrm{~F}\left(\mathrm{H}_{2} \mathrm{O}\right)_{4}{ }^{+}>\mathrm{UO}_{2} \mathrm{Cl}\left(\mathrm{H}_{2} \mathrm{O}\right)^{+}$from B3LYP calculations and $\mathrm{UO}_{2} \mathrm{~F}\left(\mathrm{H}_{2} \mathrm{O}\right)_{4}{ }^{+}>\mathrm{UO}_{2} \mathrm{Cl}\left(\mathrm{H}_{2} \mathrm{O}\right)_{4}{ }^{+}>\mathrm{UO}_{2} \mathrm{OH}\left(\mathrm{H}_{2} \mathrm{O}\right)^{+}$. Spin-orbit CI calculations at the B3LYP and LDA optimized geometries give the same ordering as from the corresponding DFT calculations. It is found that the LDA geometries are higher energy geometries at the spin-orbit $\mathrm{CI}$ level of theory especially for the $\mathrm{UO}_{2} \mathrm{OH}\left(\mathrm{H}_{2} \mathrm{O}\right)^{+}$complex. The spin-orbit CI excitation energy to the first excited state (the fluorescent state) of the hydroxide complex, calculated at B3LYP geometries, agrees well with the experimental value.

The Ohio State University (Bursten, Li)

The IBM SP2 parallel computer (NWMPP1) at the PNNL has been a powerful computer resource for our research work at The Ohio State University. By making use of the computer time granted by the grand challenge project (GC3), we were able to perform theoretical electronic structure calculations on a series of unique (and, in many cases, remarkably large) actinide compounds. Our group has developed expertise in the application of electronic structure methods based on density-functional theory (DFT) including both scalar (mass-velocity and Darwin) and spin-orbit relativistic effects, and we have already applied these methods to a variety of organoactinide and actinide coordination compounds.

\section{Calculations of the Vibrational Frequencies and Intensities of Laser-Ablated Products of

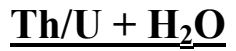

Laser-ablated Th atoms reacting with $\mathrm{H}_{2} \mathrm{O}$ during condensation in excess argon have formed a series of interesting new compounds involving Th- $\mathrm{H}$ and $\mathrm{Th}-\mathrm{OH}$ bonds. Using gradientcorrected DFT methods, we have determined the geometric structures and discussed the electronic structures and bonding of a series of laser-ablated $\mathrm{Th}+\mathrm{H}_{2} \mathrm{O}$ reaction products, including $\mathrm{HThO}, \mathrm{H}_{2} \mathrm{ThO}, \mathrm{HTh}(\mathrm{O}) \mathrm{OH}, \mathrm{HTh}(\mathrm{OH})_{3}$ and $\mathrm{OTh}(\mathrm{OH})_{2}$ species. The ground electronic states, equilibrium geometries and isotopic frequencies calculated for possible $\mathrm{Th}+\mathrm{H}_{2} \mathrm{O}$ reaction products have been calculated. Similar calculations have been performed for the $\mathrm{U}+\mathrm{H}_{2} \mathrm{O}$ reaction products $\mathrm{H}_{2} \mathrm{UO}, \mathrm{HU}(\mathrm{O}) \mathrm{OH}, \mathrm{H}_{2} \mathrm{UO}_{2}$, and $\mathrm{H}_{2} \mathrm{U}(\mathrm{O})(\mathrm{OH})_{2}$. Our calculated results are in good agreement with the observed spectra and calculated vibrational frequencies, relative absorption intensities, and isotopic shifts and strongly support the identification of these novel actinide oxyhydrides from matrix infrared spectra. 


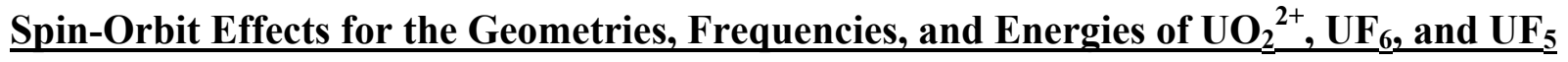

In order to examine the spin-orbit coupling effect on the geometries, vibrational frequencies, infrared absorption intensities, and reaction energetics, we have optimized the geometries and energies of $\mathrm{UO}_{2}{ }^{2+}, \mathrm{UF}_{6}$, and $\mathrm{UF}_{5}$ molecules using the SODFT method recently implemented in NWChem 4.0.1. The LDA, B3LYP, an B3PW91 exchange-correlation functionals are used, together with Stuttgart relativistic small core (RSC) pseudopotentials and basis sets for U and Dunning correlation-consistent basis sets from cc-VDZ to aug-cc-VQZ for O and F atoms. Table 2 lists the scalar-relativistic total energies (in Hartree), the vibrational frequencies, and the spin-orbit effects on these quantities (in parenthesis). The total energies and dissociation energies for $\mathrm{UF}_{6} \rightarrow \mathrm{UF}_{5}+\mathrm{F}$ were obtained.

Based on these calculations, we can draw the following conclusions:

- Spin-orbit coupling effects are basically an atomic-like property; these effects do not change significantly with the usage of different XC functionals, and there are almost no changes with different basis sets.

- Spin-orbit coupling has little effects for the geometries of these actinide molecules, as expected for the closed-shell systems, but it has strong energetic effects.

- The vibrational frequencies for these molecules are increased only by a few wavenumbers due to inclusion of spin-orbit coupling effects.

- As for main-group and transition metal systems, LDA systematically overestimating the dissociation energies, whereas GGA and hybrid functionals generate more reasonable energies.

- Relativistic small core pseudopotentials are essential in calculating actinide energetics. 